\title{
Rating Mutual Funds \\ Construction and Information Content of an Investor-cost Based Rating of Danish Mutual Funds
}

Bechmann, Ken L.; Rangvid, Jesper

Document Version

Final published version

Publication date:

2005

License

CC BY-NC-ND

Citation for published version (APA):

Bechmann, K. L., \& Rangvid, J. (2005). Rating Mutual Funds: Construction and Information Content of an Investor-cost Based Rating of Danish Mutual Funds. Copenhagen Business School [wp]. Working Papers / Department of Finance. Copenhagen Business School No. WP 2005-6

Link to publication in CBS Research Portal

\section{General rights}

Copyright and moral rights for the publications made accessible in the public portal are retained by the authors and/or other copyright owners and it is a condition of accessing publications that users recognise and abide by the legal requirements associated with these rights.

\section{Take down policy}

If you believe that this document breaches copyright please contact us (research.lib@cbs.dk) providing details, and we will remove access to the work immediately and investigate your claim. 
WP 2005-6

Rating mutual funds:

Construction and information content of an investor-cost based rating of Danish mutual funds

by

Ken L. Bechmann and Jesper Rangvid

INSTITUT FOR FINANSIERING, Handelshøjskolen i København

Solbjerg Plads 3, 2000 Frederiksberg C

tlf.: 38153615 fax: 38153600

DEPARTMENT OF FINANCE, Copenhagen Business School

Solbjerg Plads 3, DK - 2000 Frederiksberg C, Denmark

Phone (+45)38153615, Fax (+45)38153600

www.cbs.dk/departments/finance

ISBN 87-90705-97-1

ISSN 0903-0352 



\title{
Rating mutual funds:
}

\section{Construction and information content of an investor-cost based rating of Danish mutual funds}

\author{
Ken L. Bechmann and Jesper Rangvid* \\ $\underline{\text { kb.fi@cbs.dk and ji.fi@cbs.dk }}$
}

November, 2005

\begin{abstract}
We develop a new rating of mutual funds: the atpRating. The atpRating assigns crowns to each individual mutual fund based upon the costs an investor pays when investing in the fund in relation to what it would cost to invest in the fund's peers. Within each investment category, the rating assigns five crowns to funds with the lowest costs and one crown to funds with the highest costs.

We investigate the ability of the atpRating to predict the future performance of a fund. We find that an investor who has invested in the funds with the lowest costs within an investment category would have obtained an annual risk-adjusted excess return that is approximately 3-4 percentage points higher per annum than if the funds with the highest costs had been invested in.

We compare the atpRating with the Morningstar Rating. We show that one reason why the atpRating and the Morningstar Rating contain different information is that the returns Morningstar uses as inputs when rating funds are highly volatile whereas the costs the atpRating uses as inputs when rating funds are highly persistent. In other words, a fund that has low costs one year will most likely also have low costs the following year, whereas the return of a fund in a certain year generally contains only little information about the future return that the fund will generate.

Finally, we have information on the investments in different mutual funds made by a small subgroup of investors known to have been exposed to both the atpRating and the Morningstar Rating, i.e. information is provided on how investors use the two ratings. We find that investors have a clear preference for high-rated funds.
\end{abstract}

\footnotetext{
* Both authors are at the Department of Finance, Copenhagen Business School, Solbjerg Plads 3, DK2000 Frederiksberg, Denmark. Fax: (45) 3815 3615. Ph.: (45) 38152952 (Ken) and (45) 38153784 (Jesper).

We thank ATP for its financial support. The mutual fund data that we use have kindly been supplied by Morningstar through ATP. We thank Magnus Dahlquist, Martin Gruber, Martin Holmén, Michael Møller, Johannes Raaballe, market participants from the Danish mutual fund industry, in particular Mads Gosvig, Bjarne Graven Larsen, Carsten Koch, and Jesper Kirstein, as well as participants at The Multinational Finance Conference and at seminars at the Aarhus School of Business, Copenhagen Business School, The Danish Central Bank, Stockholm Institute for Financial Research, and The Danish Society of Financial Analysts for useful comments. Morningstar and atpRating are trademarks.
} 


\section{Introduction}

In 2003, there were 215 stocks listed on the Copenhagen Stock Exchange Danish stock exchange. At the same time there were 363 Danish mutual funds available to investors. In United States, there are likewise more funds than there are listed stocks. This paper introduces and analyzes a new rating that can help the ordinary investor choose between the many different mutual funds available.

The diversity of the mutual fund market makes it possible for an investor to match her wishes in terms of an asset universe (domestic stocks, foreign stocks, bonds, and so forth) with many different mutual funds. The fact that so many mutual funds are available to the investor also implies, however, that choosing particular mutual funds requires considerable investor effort in terms of collecting and analyzing information about the funds operating within the same investment universe.

To help investors monitor and choose between mutual funds, rating agencies exist. The most well-known rating agency is probably Morningstar, which assigns stars to a mutual fund based on the historical performance of the fund in comparison with its peers. The riskadjusted return of a fund upon which Morningstar bases its rating (see e.g. Blake \& Morey, 2000) is obviously important for the ultimate pay-off to the investor. The costs the investor has to pay when investing in a fund, however, plays an important role, too. For instance, one can either invest in a fund that has low costs because it follows simple strategies and consequently trades little (e.g. passive index funds) or in a fund that has higher expenses as a consequence of its more advanced asset allocation and stock picking decisions. It is not clear which of two such strategies yield the highest after-cost return to the investor, for instance, Blake et al. (1993), Gruber (1996), Carhart (1997), Dahlquist et al. (2000) report that it does not pay to invest in actively managed, and thus high-cost, funds, whereas Wermers (2000), Kosowski et al. (2005), and Baker et al. (2005) find that some active funds have stockpicking abilities, indicating some support for the value of active management.

In this paper, we describe the development of an indicator that shows the size of costs in Danish mutual funds, and we use this cost indicator to rate funds according to the size of their costs. We also relate the cost-based rating of the mutual funds to their future performances. The mutual fund rating we construct, inspired by the Morningstar Rating, has 
been given the name atpRating. ${ }^{1}$ The atpRating assigns crowns to each individual mutual fund, where the number of crowns a fund receives is determined by the costs of the fund compared to the costs of the fund's peers.

There are two main reasons why we construct a new cost-based rating of mutual funds. First, Barber et al. (2003) hypothesize that "expenses that remain out of sight are likely to remain out of mind". In other words, the way information about costs is conveyed to investors affects how investors perceive and learn about the costs of mutual fund investing. The underlying hypothesis for developing a new cost indicator is thus that ordinary investors are unable to absorb the vast amount of information about the costs of mutual fund investing, and, at the same time, the costs of mutual fund investments are relevant for the return the investor obtains from her mutual fund investment. In particular, several different types of costs have to be identified, weighted together and compared to funds with a similar investment strategy.

To help investors better understand the costs of mutual fund investing, a simple transparent cost rating would be beneficial. The second reason for developing a cost-based rating is due to our empirical findings showing that costs are highly persistent (if, for instance, a fund has low costs in one year it is also likely to have low costs the following year), whereas returns are highly volatile (if, for instance, a fund has delivered a high return this year, the likelihood of also delivering a high return the following year is not, on average, high; se also Carhart, 1997). A rating based on the most recent costs thus has the potential to contain reliable information about future costs and thereby perhaps about future returns to the investor.

After developing the indicator of the size of mutual fund costs as well as rating the funds, we test the predictive power of the cost rating for future risk-adjusted returns using data from the Danish mutual fund market for the period 1994 to 2003 . We find that the rating contains information about the future long-run performance of the funds and, in particular, that an investment in a low-cost fund, on average, is associated with a higher risk-adjusted return

\footnotetext{
${ }^{1}$ ATP (Arbejdsmarkedets Tillægspension) is a Danish pension scheme to which all Danes pay mandatory contributions. ATP is one of the largest pension managers in Europe and manages assets worth more than DKK 300 billion, or approximately USD 50 billion. Until January 1, 2005, Danes could not influence the portfolio composition of their pension savings in ATP. As of January 1, 2005, however, all Danish individuals have been allowed to allocate a part of their pension savings (the Special Pension Savings Scheme) into different mutual funds (the aggregate value of the Special Pension Savings Scheme is DKK 43 billion, or approximately USD 7 billion). To facilitate the investment decisions of individual Danes, ATP initiated the development of the atpRating. It is the development of this rating that we describe and analyze in this paper.
} 
than is an investment in a high-cost fund if the investor has an eight to ten-year investment horizon.

Today, there are two Danish mutual fund ratings: the atpRating and the Morningstar Rating. As a result, we compare the atpRatings with the Morningstar Ratings and find that the two ratings contain different information about mutual funds. We also discuss possible reasons underlying these differences, as well as implications for the predictive power of the two ratings.

Finally, evidence is provided concerning the importance of the atpRating for the inflow of cash to mutual funds. In particular, we track the size of inflows to mutual funds when savings in the Special Pension Savings Scheme (Den Særlige Pensionsordning) ${ }^{2}$ have been allocated between different individual mutual funds. The data used here have a unique feature in that we know that when investors have allocated their pension savings to different mutual funds, they have been exposed to both the Morningstar Rating as well as the atpRating because of the information provided by the Internet platform that must be used when allocating pension savings between the different mutual funds. This feature of the data allows us to present summary statistics on the inflow to funds rated by Morningstar and funds rated by the atpRating. We find that investors clearly favor choosing funds rated high by either the Morningstar Rating or the atpRating. These findings are comparable to those of Guercio \& Tkac (2001), who show that Morningstar Ratings strongly affect the inflows to US mutual funds. Given the finding that investors pay considerable attention to the rating of a fund when deciding upon where to invest, the rating of a mutual fund is important to the fund itself.

Before commencing, the reasons why the Danish mutual fund market is studied in our analysis of the cost-based mutual fund rating should also be mentioned. First and foremost, the atpRating was developed by the authors of this paper to be used by ordinary Danes when making investment decisions regarding their savings in the Special Pension Savings Scheme. Second, as just explained, data on these investment decisions allow us to investigate if investors rely on both the Morningstar Rating and the atpRating. Finally, by analyzing Danish mutual funds, we provide non-US, and in this sense out-of-sample, evidence on the issue of whether high-cost funds generate higher returns than low-cost funds, thereby contributing to the work of e.g. Blake et al. (1993), Gruber (1996), Carhart (1997), and Wermers (2000), who study US mutual funds. There is less knowledge about the relation

\footnotetext{
${ }^{2}$ See footnote 1.
} 
between the costs and performance of non-US funds. ${ }^{3}$ Given the particular characteristics of the US market, ${ }^{4}$ it is of interest in itself to know whether findings from the US also hold true in non-US countries as well.

In the Danish data used, we find that, in the short run, funds with high costs can be divided into two groups: funds with high costs that have been able to generate a very good performance and funds with high fees that have been among those that perform very poorly. In other words, investors cannot be sure, in the short run, that investing in a high-cost fund means the fund will also generate a high performance; some high-cost funds have generated a good performance, but an almost equally large number of high-cost funds have generated a low performance. In the longer run, however, it seems that funds with low costs have typically generated a better performance than funds with high costs.

After these introductory remarks, the remaining part of the paper is structured as follows. In the next section, the Danish mutual fund market is described briefly. In section 3, the cost structure of Danish mutual funds is documented and examples illustrating the influence of costs on investor returns are provided. Section 4 describes the construction of the atpRating, and in section 5, whether or not the atpRating contains useful information about future riskadjusted returns is examined. In section 6, we compare the atpRating with the Morningstar Rating and illustrate the differences in persistence of returns and costs. In section 7, we analyze how a sub-sample of investors who have been exposed to the atpRating as well as the Morningstar Rating have chosen to invest in different mutual funds. The final section offers conclusions.

\section{The Danish market for mutual funds}

In 1982, regulation of Danish mutual funds was formally grounded in Danish law. However, it was not until the second half of the 1990s that the Danish market for mutual funds really gained momentum: the total value of Danish mutual funds' holdings increased from DKK 21

\footnotetext{
${ }^{3}$ Dahlquist et al. (2000) is one of few studies that evaluate the relation between costs and performance of non-US funds. They study Swedish mutual funds and find that administration fees affect performance negatively. Christensen $(2003,2005)$, who also studies Danish mutual funds, focuses, however, on issues other than the relation between mutual fund costs and performance.

${ }^{4}$ Except from the more general differences between the US market and other markets, such as the size of the US market as compared to other markets (the US has the largest equity and bond markets in the world measured with regard to volume, trade, and so on) and the large equity premium in the US as compared to others countries (Goetzmann \& Jorion, 1999), the US is also the market with the highest number of mutual funds.
} 
billion in 1990 to DKK 257 billion in 2000, reaching a value of DKK 364 billion in 2003.5 This corresponds to an average annual growth rate of approximately $24.5 \%$. To put the size of the Danish mutual fund market in perspective, notice that the total value of the Danish stock market in 2003 was DKK 718 billion, i.e. holdings (of Danish and foreign assets) by Danish mutual funds corresponded to approximately $50 \%$ of the value of the Danish stock market. In 2003, more than 600,000 Danes, and correspondingly around 25\% of Danish households, had invested directly in Danish mutual funds.

In our investigation, both equity funds and bond funds are looked at. Equity funds and the bond funds are divided into four categories following the classification used by the ATP (listed in Appendix A). The equity funds are divided into the following categories: Danish Stocks, Global Stocks, Regional Stocks, and Other Stocks. ${ }^{6}$ The bond funds are divided into Short Bonds, Long Bonds, Global Bonds, and Other Bonds.7 The ATP categories collect different Morningstar Categories. The ATP uses fewer categories than Morningstar in order to reduce the dimensions of the investment universe faced by savers in the Special Pension Savings Scheme (Den Sxrlige Pensionsordning). In 2003, a total of 363 Danish funds exist, thereby allowing us to cover the entire Danish mutual funds market.

In Figure 1, the development of the number of Danish mutual funds during the period from 1980 to 2003 is shown in order to provide a picture of the growth in the Danish mutual funds market. Since 1995, the Danish market for mutual funds has really gained momentum, with high growth in the number of Danish mutual funds. ${ }^{8}$ In 1995, there were still less than 100 Danish mutual funds, but less than ten years later there are more than 350 funds. Since 1990, the average annual growth rate of the number of Danish mutual funds is approximately $14 \%$. Given the fact that the total value of assets controlled by Danish mutual funds increased by $24.5 \%$ on an annual basis during the 1990-2003 period, the total value of assets has increased by more than the number of funds; in other words, average fund size has increased.

\footnotetext{
${ }^{5}$ One Danish kroner (DKK) approximately corresponds to USD 0.17, i.e. the total value of assets under management by Danish mutual funds was approximately USD 62.8 billion in 2003.

${ }^{6}$ Global Stocks refers to mutual funds investing in several countries, i.e. global portfolios, whereas Regional Stocks refers to mutual funds holding stocks from individual single countries, for instance, US large cap funds, UK mid cap funds, etc.

7 Short Bonds and Long Bonds refer to Danish and Euro zone bonds. The Danish currency, kroner, closely follows the movements of the Euro and the exchange rate peg is very credible (the interest spread between Danish and German ten-year government bonds, for instance, is close to zero and has been this low since the mid-1990s). For this reason, Euro and Danish bonds are collected in one category.

${ }^{8}$ Note that it is exactly this period we concentrate on in the empirical investigations, as this is the period for which we have data on costs, as described in the following section.
} 
There are more equity funds than bonds funds in Denmark, and this has been the case every year since 1985 (each year, approximately $60 \%$ of the funds have been equity funds). In 2003, there were 212 equity funds and 151 bond funds. The largest categories are Regional Stocks, Other Stocks, and Long Bonds.

\section{Expenses}

In this section, the costs investors have to pay when investing in Danish mutual funds and the cost data used in the analysis are described.

There are three main sources of costs of mutual fund investing: Front-end load fees, backend load fees, and operating expenses. ${ }^{9}$ Because we have data on load fees and operating expenses from 1994 and onwards, the period of 1994 to 2003 is investigated in this paper. Each cost source is described in turn below.

Front-end load fee: When buying a newly issued mutual fund share, a front-end load fee (emissionstillæg) is normally charged. The load fee is denoted in percent and is a one-time, transparent up-front fee. The front-end load fee is what the investor is charged on top of the Net Asset Value (NAV) per share in order to cover the costs associated with the fund's purchase of additional assets for its newly added additional wealth. The front-end load fee ensures that the current investors in a fund are left unaffected when the fund adjusts its holdings of assets due to the new investors in the fund. Furthermore, the front-end load fee includes remuneration from the mutual fund to the bank (or other financial intermediary) that has established the sale of the mutual fund share to a private investor. ${ }^{10}$

\footnotetext{
9 In addition to these three main types of costs, there are some additional costs that we do not consider. For example, the investor may have to pay brokerage costs and a custody fee. Brokerage fees, however, depend more on the individual investor and her bank than it depends on the mutual fund and, for this reason, we disregard brokerage fees in the analysis. Similarly, we do not examine custody fees since they normally only constitute a minor part of the total costs. Finally, we recognize that the turnover of a fund's asset has implications for the return to the investor. Unfortunately, we only have turnover data for the years 2000, 2001, 2002, and 2003. Furthermore, it is not easy to obtain the associated costs of turnover. Consequently, turnover is not considered in the present study.

${ }^{10}$ In Denmark, mutual fund shares can also be traded on the Copenhagen Stock Exchange. Stocks in mutual funds traded on the stock exchange are not subject to a front-end (or back-end) load fee; only newly issued funds are subject to the fee. Given that there have been large inflows of money to the mutual funds, as mentioned in section 2, funds have mostly been issuing new shares, implying that most investors have had to pay the front-end load fees during the sample period we investigate. We thus include front-end load fees in our analysis, being aware that some investors do not have to pay the load fee if they are able to find the relevant mutual fund share on the stock exchange. Another way of interpreting our approach is that we investigate the costs to the investor if she trades directly with the mutual fund, i.e. buys a newly issued mutual fund share from the mutual fund, and sells it to the fund when terminating the investment. Finally, it should be noted that if the investor trades on the stock exchange, she will have to pay bid-ask spreads, i.e. there are other kinds of costs involved when trading on the stock exchange than the costs considered here.
} 
Table 1 provides summary statistics on the size of expenses in Danish mutual funds in 2003. The average front-end load fees are between $1.7 \%$ and $2.4 \%$ of the NAV for equity funds, whereas they are between $0.8 \%$ and $1.9 \%$ for bond funds, i.e. entry costs are higher for equity funds than for bond funds. ${ }^{11}$

Back-end load fee: When selling a mutual fund, a back-end load fee (indløsningsfradrag) can be charged.12 The fee is denoted in percent and is a one-time fee. Unlike the front-end load fee, the back-end load fee is unknown when the investor buys a mutual fund share, as the fee can change from the day of purchase to the day of sale. The averages of the back-end load fees charged by Danish mutual funds have been fairly constant throughout the sample period (not shown). Table 1 shows that back-end load fees are generally higher for equity funds than for bond funds, as is also the case with front-end load fees.

Operating expenses: Operating expenses cover mutual fund employee salaries, rental of mutual fund offices, marketing expenses, and so forth. Operating expenses are expressed as a percentage of the wealth (NAV) of the mutual fund. Table 1 shows that operating expenses are also higher for equity funds than for bond funds; for all categories of equity funds, average operating expenses make up more than one percent of NAV, whereas they make up less than one percent of NAV for all categories of bond funds. Figure 2 shows the development over time of the average operating expenses for the different categories of funds analyzed. For all equity categories, average operating expenses have increased from $1997 / 1998$ to 2003 . For instance, the average operating cost for mutual funds investing in Danish Stocks was $1.19 \%$ in 2003 , up from $0.71 \%$ in 1998; an increase of approximately $67 \% .13$ The same kind of pattern is also witnessed in the other equity categories.

For the bond categories, the pattern is slightly different. The average operating costs for the Global Bonds funds and the Other Bonds funds follow the same pattern of increases as the

${ }^{11}$ In the US, there has been a change in the way mutual funds charge their expenses. For instance, Barber et al. (2003) report that the assets under management by equity funds that charge front-end load fees have declined considerably (from $91 \%$ of the total equity controlled by equity funds in 1962 to $35 \%$ in 1999). At the same time, and most likely as a reaction to this behaviour by fund investors, mean front-end load fees have dropped from more than 8\% in 1962 to approximately 5\% in 1999 (see Figure 1 in Barber et al., 2003). In Denmark, front-end load fees have remained approximately constant throughout the sample period, i.e. in Denmark there has not been a tendency for front-end load fees to be reduced.

12 The back-end load fee is the reduction in the Net Asset Value per share that the investor must accept when selling a mutual fund share. The back-end load fee covers the costs associated with the fund selling assets in order to pay back the investor. The back-end load fee makes sure that the remaining investors in a fund are left unaffected when the fund adjusts its holdings of assets due to the lost fund investors.

${ }^{13}$ We investigated whether the increase in operating costs is due to newer funds being more expensive than older ones. This is not the case, i.e. the average costs of funds have indeed increased. 
equity funds. The operating costs of the Short and the Long Bonds funds, though, do not seem to have increased significantly during the same period. ${ }^{14}$

Before continuing, it is relevant to mention that even if the costs of investing in a Danish mutual fund have increased in recent years, the costs are still lower than in many other European countries. For instance, a comparison conducted by Morningstar (2003) showed that average operating expenses for Danish mutual funds were $1.03 \%$ in 2002, whereas average management fees for European funds were $1.18 \%$ in 2002 . The average front-end load fee was $2.47 \%$ for European funds versus $1.84 \%$ for Danish funds. Only the average back-end load fee was marginally higher for Danish funds (on average 0.66\% for Danish funds versus $0.54 \%$ for European ones). ${ }^{15}$

\subsection{The importance of expenses for investor returns: Illustrative examples}

In this section, illustrative examples of the relevance of looking at the expenses of Danish mutual fund investments are presented. This is done by calculating the hypothetical return for investors with different holding periods for funds with different expense structures. There are two reasons why we present these calculations: $(i)$ they illustrate the importance of different kinds of costs for different investment horizons which, in itself, is of relevance when trying to understand the importance of costs, and (ii) the calculations will help us choosing the weights we assign to the different sources of costs in the cost indicator we develop in section 4 .

In order to calculate investor returns after mutual fund costs have been accounted for, it is necessary to make certain assumptions about returns and costs. In the following, we assume, for simplicity, an annual return for stocks of $12 \%$ and a return of $7 \%$ for bonds, corresponding approximately to the return for the stocks and bonds markets over the last ten

14 The Danish mutual fund industry often explains the increases in operating expenses for equity funds by referring to increased competition in the mutual fund industry, which forces the mutual funds to pay more to the banks, etc. for the services provided to the mutual fund. In other words, the mutual funds claim that banks are contacted by an increasing number of mutual funds that all want to buy services from the banks, and these banks thus require higher payments from the mutual funds. Furthermore, new legislation has required that mutual funds publish more detailed reports on their performances, investment strategies, etc. which also imposes additional costs on the funds. In spite of the explanations provided by the mutual fund industry itself, the increases in operating expenses, expressed as a percentage of assets under management, nevertheless seem striking given the huge inflows of money to the mutual funds.

${ }^{15}$ The operating expenses and front-end load fees are higher in European funds than they are in Danish funds, also if one splits up the funds into bond and equity categories. 
years. However, it can be argued that these returns are on the high side when modeling future expected returns, which will just increase the relative importance of the costs.

The calculations that follow highlight how costs potentially affect the return from mutual fund investments rather than evaluate whether high or low costs are warranted. In other words, we keep a constant rate of return on bonds and stocks regardless of the level of costs. In subsequent sections of this paper, we evaluate whether high costs empirically have implied higher returns.

The realized return is calculated after expenses for investors investing in funds with low costs and for investors investing in funds with high costs. The cost figures for 2003 shown in Table 1 are used in the examples.

Low-cost funds are defined as funds whose costs equal the minimum cost in a specific category. For instance, in our example, a low-cost mutual fund investing in Danish Stocks is assumed to have an annual operating cost of $0.48 \%$, a front-end load fee of $0.25 \%$, and so forth. High-cost funds are defined as funds whose costs equal the maximum cost in a specific category (for instance, in our example, a high-cost mutual fund investing in Danish Stocks is assumed to have an annual operating cost of $2.09 \%$ and so forth). In our illustrations, we pick the highest (and lowest) costs charged by any fund in 2003, thereby implicitly assuming that the fund charging the highest (lowest) operating expenses in 2003 also charged the highest (lowest) load fees. This need not have been the case, of course, but serves to illustrate the potential maximum impact of costs.

Consider an investor who invests in a Danish Stock mutual fund. We assume that the pre-cost value of the mutual fund stock is 100 . With an assumed return of $12 \%$ per annum, the precost value of the stock is thus 112 after one year. To buy a Danish mutual fund stock with low (high) costs, the investor must pay 100, plus the front-end load fee, which is 0.25 (2.61). The net value of the stock after one year is the stock market value minus operating costs, i.e. 112-0.48 (2.09) =111.52 (109.91). When selling the stock, the investor may be charged the back-end load fee, i.e. for a low-cost fund $111.52 \cdot(1-0.0020)=111.30$ will be received. For a high-cost fund, the investor receives $109.91 \cdot(1-0.0136)=108.42$. The return from the low-cost fund can now be calculated as $111.30 / 100.25=11.02 \%$ and the return from the high-cost fund as $108.42 / 102.61=5.66 \%$. In other words, if the investor has a one-year horizon, the return from the stock market gain of $12 \%$ is reduced to $11.02 \%$ if investing in a low-cost fund, whereas the return is reduced from $12 \%$ to only $5.66 \%$ if investing in a high-cost fund. The 
return from the high-cost fund is thus less than half of the return from the market if the horizon is one year only.

Calculations are performed for investors with one, five, and twenty year horizons. Table 2 shows the annual returns on these investments, the fractions of investor return to actual market returns, and the present value of the two load fees relative to the present value of the total costs under the stylized assumptions mentioned above. The present value is calculated using a discount rate of $5 \%$, but the results are not very sensitive to changes in this rate.

One way to gauge the importance of costs when investing in Danish mutual funds is to look at the difference between the fractions of mutual fund returns to actual market returns for low and high-cost funds. With the most extreme example, for instance, the investor gets 95\% of the actual bond market return (6.67\% instead of 7\%) if low-cost Other Bonds funds are held for one year. On the other hand, the investor only gets $1 \%$ of the actual bond market return if high-cost Other Bonds funds are purchased. ${ }^{16}$

It is interesting to note the relation between the investment horizon and the ratio of mutual fund investor annual returns to actual annual market returns. Consider for instance an investment in a high-cost mutual fund investing in Danish Stocks. If the investor has a oneyear horizon, mutual fund costs account for $53 \%$ of the actual annual market return. However, if the investor has a twenty-year horizon, mutual fund costs account for "only" $19 \%$ of the market return. The reason for this decline in the relative importance of expenses is that load fees lose their importance the longer the investment horizon because load fees are paid only once (when entering and leaving the fund, respectively), i.e. the longer the mutual fund is kept, the less important the load fees are for the return that is eventually realized, all else equal. On the other hand, as operating expenses are paid every year, operating expenses gain relative importance the longer is the horizon.

Similarly, Table 2 also shows that the importance of the load fees relative to operating expenses also depends on the type and cost structure of a fund as well as the investment horizon. For example, with an investment horizon of five years, the load fees will account for close to $30 \%$ of the total cost (of high-cost Danish stock investments), whereas they would only account for approximately $10 \%$ of the total cost with a twenty-year investment horizon.

\footnotetext{
16 Of course, the return of seven percent per annum is not what an investor could achieve if she invested on her own instead of investing through a mutual fund, as there are costs associated with investing directly, too. What the table shows, as mentioned, is how mutual fund costs potentially affect the return to the investor in relation to the return on the market.
} 


\section{Constructing the atpRating}

In order to construct a cost rating, it is necessary to weight the different sources of costs involved in mutual fund investments into one cost indicator. Based on this indicator, we will assign an atpRating to the different funds. To accomplish these tasks, we need to, first, develop the relevant cost-indicator and, second, sort the funds within the different rating categories according to the size of the cost indicators of the individual funds.

\subsection{The cost indicator}

As mentioned, there are three main sources of costs associated with mutual fund investments: Front-end load fee, back-end load fee, and operating expenses. It is necessary to give each of these costs appropriate weights such that an indicator can be constructed. The theoretical cost indicator $\mathrm{CI}$ of a fund in some year $t$ thus takes the form

$$
C I_{t}=\gamma_{1} \text { Ope }_{t-1}+\gamma_{2} \text { Front }_{t}+\gamma_{3} \text { Back }_{t},
$$

where Ope.t-1 is the operating expenses of the fund during year $t-1$, Front $t_{t}$ is the front-end load fee, and Back is the back-end load fee. The load fees are both measured as the values valid in year $t$. The $\gamma$ s are the weights to be put on the different components of the cost indicator.

The examples from section 3.1 illustrate that the investment horizon matters with regard to the importance of the different costs involved in a mutual fund investment. For instance, the return for an investor with a short horizon is greatly affected by the load fees, whereas this is not as often the case for an investor with a longer horizon. These facts imply that there is no uniformly correct way to determine the weights of the cost indicator, as the "correct" weights will change depending on the investment characteristics of the individual investor. Thus, in the following, we first choose weights, and, later, investigate how robust the atpRating is towards changes in the chosen weights. In our choice of weights, we recognize that:

(i) The back-end load fees that the investors may be charged when leaving the fund are not known at the time of the purchase of the mutual fund share (as mentioned in section 3). On the other hand, front-end load fees are known when purchasing the fund. 
(ii) Back-end load fees and front-end load fees are correlated, i.e. a large part of the information contained in back-end load fees is also contained in front-end load fees. ${ }^{17}$

For these two reasons, we decided to put zero weight on the back-end load fee, and include the front-end load fee with a "double-weight" in the cost rating. Furthermore, we note that:

(iii) Operating expenses are paid each year, whereas load fees are paid only once.

For this reason and due to the results on the relative importance of the load fees in Table 2, a higher weight is put on operating expenses. On the basis of these considerations, the baseline specification of the cost indicator that we work with takes the form:

$$
C I=0.7 \text { Ope. }+0.3 \text { Front }+0 \text { Back } .
$$

In other words, operating expenses weight 0.7 in the costs indicator, front-end load fees weight 0.3 , and the coefficient to the back-end load fee is set at zero. The column entitled "PV(Load Fees) relative to PV(Total Costs)" in Table 2 shows that the present value of load fees for many of the categories we use make up approximately 30 percent of total costs with a five-year investment horizon; in other words, the $30 \%$ and $70 \%$ weights generally correspond to an implicit investment horizon of approximately five years.

In addition to our baseline specification, we also discuss results using a cost indicator where operating expenses weight 0.9 and front-end load fees weight 0.1 (approximately corresponding to an investment horizon of 15 to 20 years), as well as an indicator where operating expenses are given full weight. Given the results on the investment horizons implicitly determined by the different weights, we have decided not to report any results for a cost indicator where the weight on operating expenses is lower than $70 \%$. However, such cost indicators do lead to results similar to those discussed later in this paper.

\subsection{The atpRating}

As the final step in the rating process, all funds are sorted according to the size of their cost indicator in relation to the cost indicators of the other funds in the same ATP-category. One crown, the high-cost designation, is assigned to the ten percent of the funds with the highest costs (as measured by the size of the funds' cost indicators) within their ATP-category. The next $22.5 \%$ of funds within an ATP-category are assigned two crowns. The next $35 \%$ are the funds that have costs around the value of the average cost indicator of their ATP-category.

\footnotetext{
17 The correlation across funds between the average back-end and front-end load fees over 2001, 2002, and 2003 is 0.52 .
} 
The next $22.5 \%$ are assigned four crowns, and the ten percent of the funds with the lowest costs within an ATP-category are assigned five crowns. The percentages used for the rating of the funds are the same percentages as Morningstar uses for the rating of funds when assigning stars to mutual funds.

Our total sample period is 1994-2003, as mentioned. We rated the funds in 1994, 1995, 1998, and 2000, i.e. ten years before the last year in the sample, eight years before the last year in the sample, five years before the last year, and three years before the last year in the sample. ${ }^{18}$ We decided each ATP-category should contain at least ten funds before it made sense to rank them. From Table 3, which shows the numbers of funds in the different ATPcategories for the different time horizons, it can be seen that there are ratings within all categories using three years of data, whereas Global Stocks, Regional Stocks, and Long Bonds are the only groups that have ratings for the ten-year horizon.

\subsubsection{Robustness of the atpRating towards changes in the weights}

The first analysis of the atpRating that we perform is to examine how sensitive the ratings of the funds are with respect to the choice of weights in the cost indicator. Table 4 reveals how the ratings of funds in 2003 change when the weight put on operating expenses is altered from 0.7 to 0.9 (which corresponds to a change in the weight on operating expenses of $28.5 \%$, i.e. a considerable change) and consequently the weight on the front-end load fee from 0.3 to 0.1 .19

Table 4 reveals, for instance, that there are 25 funds that get an atpRating of one crown regardless of whether the weight on operating expenses is 0.7 or 0.9 . Nine funds change from rating 1 to rating 2 when the weight is changed from 0.7 to 0.9 , and two funds change from rating 1 to 3 when the weight is changed from 0.7 to 0.9 . No fund changes from rating 1 to rating 4 or 5 .

Altogether we find that $63 \%$ of the funds remain in the same rating category regardless of whether the weight on operating expenses is set at 0.7 or 0.9 . Thirty-four percent of the funds change one rating category (either up or down), when the weight is changed from 0.7 to 0.9 , and $3 \%$ of the funds change two rating categories. No fund changes more than two rating

\footnotetext{
18 When analyzing ten-year future performance, we should in principle calculate the cost indicator and the ratings in 1993. Due to cost data availability, we ranked the funds in 1994, however.

${ }^{19}$ Due to the lack of data on operating expenses for 20 newly started funds, we are only able to rate 343 funds (out of a total of 363 funds) in 2003.
} 
categories. Overall, $97 \%$ of the funds remain in their rating category or change one rating category.

If the weight of the cost indicator is changed from 0.7 to 1.0 (results not shown in order to save space), $93 \%$ of the funds remain in the same rating category or change one rating category ( $51 \%$ remain in the same category and $42 \%$ change one category).

One reason why so relatively few funds change rating category when the weights are changed is due to the fact that the correlation between operating expenses and front-end load fees across funds is close to 0.5 for the 2001-2003 period. In other words, a fund that has a relatively high (low) front-end load fee is likely to have relatively high (low) operating expenses, too. Changing the weight to the front-end load fee, thus, will not change the relative sizes of the cost indicators of the funds much.

All in all, we conclude that the atpRating of the funds is rather robust with respect to the chosen weights in the cost indicator.

\section{Does the atpRating predict future performance of the funds?}

The atpRating rates funds according to the size of their costs and in this way summarizes information about the different kinds of costs investors have to pay in a transparent fashion. Given that there are several kinds of costs, the hypothesis put forward by Barber et al. (2003) is that ordinary investors perhaps can have difficulties in evaluating the justification of these costs and, in particular, the sizes of the costs in relation to the costs of other funds. In this light, the atpRating alone can be argued to serve a useful purpose by providing easily accessible information about costs to potential investors.

In addition to using the rating for this purpose, one would also like to know whether the information about costs that the rating contains is relevant for predicting future returns. The idea underlying this hypothesis is that if two funds generate similar pre-cost returns, the return to the investor, per definition, will be higher if the investor invests in a fund with relatively low costs today, and these costs are persistent such that low costs in the current period are associated with low costs also in future periods. ${ }^{20}$ In this section, we will thus investigate whether a particular atpRating of a fund in a current period reveals information about the future performance of the fund.

\footnotetext{
${ }^{20}$ We evaluate the persistence of costs in section 6.2.
} 


\subsection{Measuring fund performance}

Before investigating the predictive content of the atpRating, we briefly explain how riskadjusted returns are measured.

Given risk-return trade-offs, risk averse investors care not only about the return they receive, but also about the certainty with which they can expect to receive those returns. For this reason, it is now standard to look at risk-adjusted performance measures (a fund showing high return could also be a risky fund - a possibility that is taken into account in the analyses that follow). The standard performance measure used, and the one applied here, is Jensen's alpha, which is the constant $\alpha_{i}$ from the time-series regression

$$
r_{i}-r_{f}=\alpha_{i}+\beta_{i}\left(r_{p}-r_{f}\right),
$$

where $r_{i}$ is the total return to the investor from holding fund $i, r_{p}$ is the return on a benchmark portfolio, $r_{f}$ is the return on the risk-free asset (the one-month Copenhagen Interbank Offered Rate, CIBOR1m, as our return data are sampled monthly ), and $\beta_{i}$ is the beta of the fund with respect to the benchmark portfolio. ${ }^{21}$

A decision must be made about what the benchmark portfolio is and about what period is used to generate the alphas and the betas. In the US literature, it is now customary to generate alphas from a four factor model (Gruber, 1996; Carhart, 1997; Wermers, 2000), i.e. to use several different benchmark portfolios. In the US literature, however, focus is often restricted to US equity funds only. In this study, we have both equity funds, bonds funds, money market funds, and so forth. Furthermore, we have funds investing in Denmark only and funds that hold assets from many countries. In other words, applying the same model for determining expected returns of all funds would not be appropriate as the benchmark portfolios will vary from one mutual fund class to another.

The approach we follow below is to keep the model as simple as possible and regress each fund's excess returns on the excess return of one single benchmark portfolio. However, we also rely on the insight of the US literature that one cannot expect the same single benchmark portfolio to capture the many facets of returns from many different funds with many varying characteristics. For this reason, we regress the return from fund $i$ on the return from the Morningstar Category associated with fund $i$

$$
r_{i}-r_{f}=\alpha_{i}+\beta_{i}\left(r_{p, j}-r_{f}\right)
$$

${ }^{21}$ Mutual fund returns are defined as the percentage changes in the Total Net Asset Values of the funds plus dividends if they have been paid out. The Total Net Asset Value of a fund is the total value of the assets that the fund holds taking into account the operating expenses of the fund, i.e. all else equal higher operating costs of a fund lead to lower Net Asset Values and thus returns. 
where $r_{p, j}$ is the return from the Morningstar-defined category- $j$ portfolio to which fund $i$ belongs. ${ }^{22}$ The major advantage of this approach is that the performance of fund $i$ is measured in relation to the performance of its closely related peers. ${ }^{23}$ In this light, it is also relevant to mention that the Morningstar Categories constitute relevant benchmarks for the funds. For instance, the average $R^{2}$ across all regressions used to generate the alphas is 0.85 when estimating the models using three years of data, i.e. a Morningstar Category return captures on average around $85 \%$ of the variation in the return of a fund during the 2001-2003 period. For the alphas estimated using five years of data, the average $R^{2}$ is 0.81 and with eight years of data the average $R^{2}$ is 0.77 .

We examine alphas based on estimations using three, five, eight, and ten-year periods of observations.

\subsection{Testing the atpRating}

Three kinds of analyses are presented in order to shed light on the question of whether the atpRating contains information about the future performances of mutual funds. First, the future performance of a fund is graphed together with the fund's historical atpRating. Second, simple summary statistics are presented of the average differences in future performance across classes of high-cost versus low-cost funds. Finally, the cross-fund regression approach of Blake \& Morey (2000) is used to test whether the atpRating contains information about the future performance of the funds.

\subsubsection{Graphically illustrating the predictive power of the atpRating}

To illustrate the predictive power of the atpRating, consider 1994 as the base year. We rank and assign crowns to the funds based on the sizes of their cost-indicators in 1994, as described in section 4. We then plot the rating of a fund in 1994 against the alpha of the fund where the alpha is generated for the 1994-2003 period. We are interested in evaluating whether the alphas, based upon the 1994-2003 period, on average are higher for those funds that in 1994 were assigned, for instance, five crowns (i.e. the 10\% of the funds with the lowest

\footnotetext{
22 There are 53 Morningstar categories in the data used. The categories and their summary statistics are listed in Appendix A.

${ }^{23}$ Note that Morningstar bases its stars for a fund on the performance of this fund in relation to the performance of other funds within the category. We thus follow this approach when estimating the alphas.
} 
costs in 1994), compared to the average alpha of those funds that were ranked, for instance, with one crown in 1994. We perform the same exercises using 2000 as starting year.

In Figure 3, we present the alphas of the funds when measured for the 1994-2003 period against their atpRating in 1994; the alphas are monthly alphas, i.e. they measure the average monthly risk-adjusted excess return obtained for the 1994-2003 period. Figure 3 reveals a clear tendency that funds with higher ratings in 1994 (and thus lower costs in 1994) have done better during the 1993-2004 period than funds with lower ratings (and thus higher costs), perhaps with the exception of the large dispersion of alphas for the funds in atpRating category 2. In particular, funds assigned, for instance, three crowns in 1994 seem to have higher alphas than funds assigned one crown in 1994; funds in group four, on average, did better than those in group three, and funds in group five, on average, did better than those in group 4. In order words, there seems to be indications - on the basis of this first graph - that funds with higher ratings (i.e. lower costs) yield a better future long-run (ten-year) performance than do funds with lower ratings.

Figure 4 is constructed like Figure 3. However, in Figure 4, three-year alphas are shown together with the atpRating of the funds in 2000. The figure reveals that there is no clear pattern in the alphas when comparing alphas of lower rated funds with those of higher rated funds. In other words, there seems to be less information about future returns with short horizons than there is when evaluating a fund's performance over long horizons (as in Figure 3). There are funds in rating category 1 (i.e. those with the highest costs in 1994) that have performed very well, but there are also funds in category 1 that have obtained very low alphas. In other words, high costs do not necessarily generate high performance. This is in accordance with the findings in Gruber (1996) for the US. But high costs do not necessarily imply low performance either. Instead, high costs are not only associated with funds that have generated a high future risk-adjusted short-run performance, but also with funds that have generated a very low future risk-adjusted short-run performance.

Prior to discussing the reasons for the differences in results that are obtained when using three years of data versus ten years of data, in section 6.2, we will examine whether the differences visualized in Figures 3 are actually statistically significant.

\subsubsection{Testing the atpRating using simple t-tests}

The differences in the average alphas across atpRatings can be tested in a more systematic way. The upper part of Table 5 shows the average alphas of the funds for different rating 
categories for three-year (i.e. alphas for the period 2001-2003 classified as based on the atpRating in 2000), five-year (i.e. based on the atpRating in 1998), eight-year (based on the atpRating in 1995), and ten-year horizons (based on the atpRating in 1994). In the lower part of the table, the differences in average alphas for funds in atpRating categories 1 (with the highest costs) and 5 are shown - in row " $5-1$ " - together with the probability values (below the test statistics) from t-statistics of tests of the hypotheses that the differences are statistically distinguishable from zero. In row " $(4+5)-(2+1)$ ", the difference between the average alphas of the $32.5 \%$ of funds with the highest costs (rating category 1 and 2 ) and the average alphas of the $32.5 \%$ of the funds with the lowest costs (rating category 4 and 5) are shown (with probability values from t-tests of zero difference below).

The general pattern revealed by the table is that the differences between the alphas are not significantly different from zero on the shorter three and five-year horizons, i.e. on the shorter horizons there is no statistical evidence that higher-cost funds have performed either worse or better than lower-cost funds. The signs are not robustly estimated at the shorter three and five-years horizons; sometimes the difference is positive (implying that low-cost funds outperform high-cost funds) and sometimes the difference is negative.

Long horizons are different, however. At the eight and ten-year horizons, the point estimates of all differences, both the means and the medians, are positive. A positive difference indicates that funds with higher ratings, and thus lower costs, have delivered a superior performance compared to funds with higher costs in the eight or ten years following their cost rating. In particular, at the ten-year horizon, when comparing both the $10 \%$ of funds with the lowest costs with the $10 \%$ of funds with the highest costs and when comparing groups $4+5$ with groups $1+2$, the differences between the means are statistically different from zero, i.e. the superior performance of low-cost funds is not random. At the eight-year horizon, the point estimates of the differences are all positive regardless of whether means or medians are studied. At the eight-year horizon, not all means are statistically different from zero, however.

\subsubsection{Testing the atpRating using regression analyses}

A final way to test the predictive power of the atpRating is to follow the approach of Blake \& Morey (2000), i.e. running multivariate cross-sectional regressions of alphas on dummy variables that pick out four of the five categories. The advantage of this approach, in comparison to the simple t-tests presented above, is that the Blake \& Morey (2000) approach 
use all the funds in each single regression, and not only the funds in certain selected rating categories (for instance, funds in rating category 1 and 5 only, as in row "5-1" of Table 5).

The regressions are undertaken using the ratings of the funds in 1994, 1995, 1998, and 2000, where the ratings in the individual years are obtained as explained in section 4 . For a given year, we create a dummy variable that picks out the funds with two crowns, another dummy variable that picks out the funds with three crowns, etc. No dummy variable is created that picks out the funds with one crown (the funds with the highest costs), i.e. the funds with one crown are used as the reference funds with which other lower-cost funds are compared. To explain the procedure, consider the rating of funds in 1994. We regress the alphas of the funds on the four dummies (that pick out funds according to their atpRating category classification in 1994), remembering that the alphas are based on the period from 1994 to 2003 , i.e. on the risk-adjusted performance of the fund in the ten years following the rating. In this way, the regressions provide evidence on the information about future returns that the atpRating contains. The same procedure is followed using 1995, 1998 and 2000 as the starting year, where the alphas are estimated over the following eight, five and three years, respectively. The regressions we perform thus look as follows

$$
\alpha_{i}=\delta_{1}+\delta_{2} D_{2}+\delta_{3} D_{3}+\delta_{4} D_{4}+\delta_{5} D_{5}
$$

where $D_{2}$ is a dummy picking out those funds that belong to atpRating group 2 (the group of funds with the second-highest costs), $D_{3}$ picks out those funds that belong to rating group 3 , and so forth, up to $D_{5}$ which picks out the funds with the lowest costs within their ATPcategory. If the atpRating contains information about future returns, we expect that funds with lower costs also have higher alphas (perform better), i.e. we expect $\delta_{2}$ to $\delta_{5}$ to be positive, and we expect $\delta_{3}$ to be more positive than $\delta_{2}$, $\delta_{4}$ to be more positive than $\delta_{3}$, and $\delta_{5}$ to be more positive than $\delta_{4}$.

The results from these regressions are presented in Table 6 . We present results using both simple OLS regressions and robust regressions. Results from robust regressions are presented in order to check the robustness of the OLS regressions with respect to the influence of outliers (see, for example, Holland \& Welsch, 1977).

The results contained in Table 6 (again) reveal that rating funds on the basis of their cost indicator contains information about the long-term risk-adjusted excess returns of the funds. In more detail, looking at the OLS regression results for risk-adjusted returns over the three years as based on the values of the cost indicator in 2000 (the estimates presented in rows " 3 year"), all coefficients have the "wrong" sign in the sense that funds with lower costs than 
those of group one also experienced lower risk-adjusted returns, i.e. the opposite of what would be expected. The same basically holds for the five-year returns. Furthermore, signs and significance levels change if estimation techniques are changed, indicating that some outliers influence the results, see also Figure 2.

For the eight and ten-year returns, however, the story is different. In particular, the rating of funds in 1995 implied that funds in group 5 (the funds with the lowest costs in 1995) actually obtained statistically significant higher risk-adjusted excess returns for the 1996 to 2003 period than funds with the highest costs (those in group 1) in 1995. In other words, out of sample, the funds with the lowest costs did, on average, better than the funds with the highest costs. The rating of funds in 1994 also had some predictive power. The funds in the group with the lowest costs, group 5, obtained significantly higher risk-adjusted excess returns over the out-of-sample period 1994-2003 than the funds in group 1 (with the highest costs). Furthermore, for the eight and ten-year regressions, the results are generally robust towards the influence of outliers, as the OLS and robust estimation techniques generally give similar results.

What is the interpretation of the coefficients? Consider the estimate of $\delta_{5}$ as an example. The estimate of $\delta_{\underline{5}}$ gives the difference between the alphas generated by funds in groups 1 and 5 respectively, i.e. an estimate of $\delta_{5}$ of 0.326 implies that the average monthly alpha of the funds in group 5 is $0.326 \%$ higher than the average alpha of the funds in group 1 . In other words, had an investor in 1994 invested in the funds in group 5 (those with the lowest costs in 1994 within their ATP-category), she would have obtained an annual risk-adjusted excess return that is approximately $3-4 \%$ higher than if she had invested in funds in group 1 (with the highest costs within their ATP-category in 1994) measured over the period from 19942003. Our findings are thus economically significant, too.

We find that the coefficient to the dummy picking out the lowest-cost funds $\left(\delta_{5}\right)$ is significantly positive using the 1994-2003 out-of-sample period. We also find that the coefficients $\delta_{2}, \delta_{3}$, and $\delta_{4}$ are estimated to be positive with regard to long horizons, but that they are not significantly different from zero $\left(\delta_{4}\right.$ is significant at a $11 \%$ level, however). The finding that the lowest-cost funds have a significantly superior long-run out-of-sample performance in relation to the highest costs funds, but also that funds in groups 2, 3, and 4 do not have significant coefficients (even when the signs to the coefficients are positive and the $\delta$ s are increasing in magnitude) is in line with the results from Blake \& Morey (2000) on the predictive content of Morningstar Ratings. Blake \& Morey (2000) report that Morningstar 
Rating groups 1 and 2, i.e. the rating groups picking out the funds with the historically lowest returns within their Morningstar Categories, predict low risk-adjusted returns out-ofsample in comparison to the return of funds in Morningstar Rating group 5 (with the historically highest returns), whereas Morningstar Rating groups 3 and 4 have no predictive power. In other words, we find that our atpRating predicts, at least to some extent, returns on the lowest-cost funds out-of-sample, and Blake \& Morey (2000) report that Morningstar Ratings predict, at least to some extent, the future returns of the historically best performing funds in US.

\subsection{Robustness checks}

A number of robustness checks have been performed. ${ }^{24}$ First, we evaluated whether our basic finding (that low-cost funds outperform high-cost funds in the long run) arose because the funds that are in the sample for the full 1994-2003 period are in some way special. As can be seen from Table 6, there are 268 funds for which we have data during the period 20012003. However, there are only 42 funds that could be rated in 1994 and where we have data during the full 1994-2003 period. In order to evaluate whether these 42 funds are special or whether the findings presented in section 5.2 really are due to a horizon effect, we conducted regressions such as those in Table 6 for the 42 funds that are available during the complete sample period only. The results showed that at the three-year horizon, the estimates were all insignificant, whereas they were significant and positive for long horizons. The only difference from the results in Table 6 was that when looking at the 42 funds for which there are data for the complete ten-year sample, significantly superior performance is shown by the funds in group 5 for the five-year horizon, too. Overall, we conclude that when looking at funds present in the complete sample period, a significantly superior performance is not obtained over a short three-year horizon by investing in funds with the lowest costs. If the horizon of the investor is longer, however, a superior performance is obtained, on average, by investing in funds with low costs.

\subsubsection{Other weights in the cost indicator}

Are the results robust if we choose other weights in the cost indicator? To answer this question, we rate the funds using the alternative cost indicators where operating costs

\footnotetext{
${ }^{24}$ Tables documenting the results described in this section are not shown in order to save space. The results can of course be obtained upon request.
} 
weight 0.9 and front-end load fees 0.1, CI=0.9Ope.+0.1Front as well as the indicator taking the form $C I=1 O p e$. + Front . Overall, the results are fairly robust towards the choice of other weights in the cost indicator in the sense that the results from the robust regressions are similar to the results in Table 6.

\section{Comparing the atpRating with the Morningstar Rating}

We have developed a new rating for mutual funds. It is consequently of interest to know how the atpRating distinguishes itself from other ratings that are available for Danish mutual funds, i.e. the Morningstar Rating. The Morningstar Rating is based on historical performance measured in terms of the risk-adjusted returns of mutual funds. Morningstar rates Danish mutual funds based upon the previous three years of risk-adjusted performance. ${ }^{25}$ The risk-adjusted performance of a Danish mutual fund is compared to the risk-adjusted performance of other European funds within the same Morningstar Category. If the fund belongs among the $10 \%$ of European funds within the category that has obtained the best performance, the fund receives five stars. If the fund belongs among the best next $22.5 \%$ of European funds, the fund receives four stars and so forth. The percentages used for classifying funds into the different categories in the atpRating are thus borrowed from the Morningstar percentages.

The important differences between the atpRating and the Morningstar Rating are thus as follows:

- Morningstar rates funds on the basis of historical risk-adjusted returns. The atpRating rates funds on the basis of costs only.

- Morningstar rates Danish mutual funds on the basis of the previous three years of riskadjusted returns of a fund. The atpRating rates funds on the basis of the previous single year's fees. ${ }^{26}$

\footnotetext{
${ }^{25}$ For ratings of US mutual funds, Morningstar Ratings are based upon the historical performance of a fund during three different periods: the last ten years, the last five years, and the last three years (see e.g. Morey, 2002). For each period, the fund receives a Morningstar star. The overall Morningstar Rating of a fund is then based upon a weighted average of the ratings of the fund for the three periods. If a fund in the US has existed for less than five years, but more than three, the overall Morningstar Rating of the fund is the rating based upon the last three years. It is this last Morningstar Rating strategy that is used for all Danish mutual funds, even though some Danish mutual funds have existed for more than ten years.

26 As mutual fund returns are obtained after operating expenses, Morningstar risk-adjusted performance measures implicitly subsumes operating expenses. In other words, in the atpRating, the size of fees is the only parameter upon which funds are rated. In Morningstar, fees are implicitly included in combination with risk-adjusted returns when rating funds.
} 
- Morningstar compares the performance of Danish mutual funds with the performances of other European funds within the same Morningstar investment category. The atpRating compares the costs of Danish mutual funds with those of other Danish mutual funds within the same ATP investment category.

Morningstar only started rating Danish mutual funds in 2001, i.e. data on Morningstar Ratings of Danish mutual funds exist for 2001, 2002, and 2003 only. As a result, it is not possible to do any serious analyses of whether Morningstar predicts future performance given this short period of information on Morningstar Ratings. What we can do, however, is to evaluate whether the atpRating and the Morningstar Rating contain the same information, or whether the two ratings actually contain different information.

Table 7 shows the distribution of funds across the two ratings in 2003. Consider, for instance, funds that have been assigned category 1 (the $10 \%$ of funds with the highest costs) in the atpRating in 2003. Table 7 shows that the Morningstar Rating did not assign any of these funds to its category 1 . Indeed, $4.2 \%$ of the funds that were assigned category 1 in the atpRating were assigned category 2 in Morningstar, 37.5\% category 3 in Morningstar, 29.2\% category 4 in Morningstar, and the remaining 29.2\% were assigned category 5. In other words, $29.2 \%$ of the funds that had the highest costs in 2003 were also in the Morningstar category of funds that have had the best risk-adjusted performance for the last three years. We have performed the same exercise for the relation between fund rankings in 2001 (not shown to save space). The overall picture shows again that the majority of the funds are not placed in the same category in the atpRating and the Morningstar Rating. The investor thus gets different information when considering the cost-based atpRating, based upon last year's costs, versus the performance-based Morningstar Rating that rates funds based on the last three years of risk-adjusted performance.

The finding that funds with high costs (atpRating 1) can be placed in the Morningstar categories of funds with the very best performance, but also in categories of funds with rather poor performance (e.g. in Morningstar category 2), links up well with the findings presented in Figure 4 on the relation between the atpRatings in 2000 and the future alphas calculated using data from the 2001-2003 period. In Figure 4, we concluded that on short horizons there are funds with high costs that have performed well, but that there are also 
funds which have performed badly. The relation between Morningstar Ratings and atpRatings in this section mirrors this finding. ${ }^{27}$

\subsection{Which rating should the investor rely upon?}

In the end, the answer to the question of which rating to rely upon must be based on the empirical evidence. In Tables 5 and 6, we have presented evidence that the atpRating contains information about future risk-adjusted returns over long horizons (eight to ten years), and, in particular, for these horizons, funds with the lowest costs have yielded higher performance than funds with higher costs. Given the short history of Morningstar Ratings in Denmark, it is necessary to wait before it is possible to present analyses of whether Morningstar Ratings contain information about the long-horizon performance of Danish mutual funds.

What we can do, however, is refer to the literature on whether Morningstar Ratings contain relevant information about the future performance of US mutual funds, where longer periods of observations on fund performances are available. This issue has been examined in Blake \& Morey (2000), Morey (2002), and Vinod \& Morey (2002). These authors evaluate whether Morningstar contains information about future returns from mutual funds. In summary, they find that Morningstar is best at predicting losers, but not so good at predicting winners. A fund receiving only a few Morningstar stars has a tendency to perform poorly in the future, whereas the highest rated funds often do not show superior performance compared to funds rated as three or four star funds. As mentioned, the findings on the predictive performance of the atpRating are that the atpRating predicts superior performance of its highest-rated funds over investment horizons of eight to ten years. Therefore, it will be interesting in the future to compare the predictive power of Morningstar Ratings with those of the atpRating as well as to examine whether the use of both ratings can improve the identification of mutual funds that perform well.

\subsection{Why are there differences between the ratings?}

The Morningstar Rating rates funds on the basis of the last three years of risk-adjusted returns where these risk-adjusted returns are calculated after implicitly taking into account costs, whereas the atpRating is based solely upon last year's costs.

27 Another aspect worth paying attention to when reading Table 7 is that few funds are assigned Morningstar Rating group 1. The explanation is that Danish funds are traditionally rated fairly high in European comparisons. For instance, in December 2003, the average number of stars assigned to Danish funds was 3.16, which was the second-highest average among 14 European countries. 
One reason why there are differences between the two ratings is that costs are more persistent than returns and market-adjusted returns are. In this section, we examine, in particular, the variation over time of expenses and market-adjusted returns by relating across funds expenses lagged once with current expenses and market-adjusted returns lagged once with current market-adjusted returns. Market-adjusted returns are measured as the return in excess of the return of a fund's peers (measured by the return on the Morningstar Category to which the fund belongs).

The variations are illustrated in Figures 5 and 6 . At first glance, the figures give a strong indication of the high persistence in expenses (expenses from the previous and current year are scattered closely around the regression line) and a very low persistence of marketadjusted returns (market-adjusted returns from the previous and current year are spread all over the regression line). Another way of illustrating this is by presenting the results from the regression of last year's expenses on this year's expenses across funds and years. This regression generates the following result (with t-statistics in parentheses below)

$$
\text { Expense }_{t}=\underset{(13.62)}{0.18}+\underset{(72.52)}{0.89} \text { Expense }_{t-1} \text {, }
$$

with an $R^{2}$ of 0.77 . The corresponding regression for market-adjusted returns is

$$
\left(r_{t}-r_{p, j, t}\right)=\underset{(1.13)}{0.002}+\underset{(1.11)}{0.026}\left(r_{t-1}-r_{p, j, t-1}\right),
$$

with an $R^{2}$ of 0.00 . These results thus indicate that the persistence in expenses is highly significant, and a large portion of the cross sectional variation in this year's expenses can be explained using last year's expenses $(77 \%)$, whereas this is not the case for returns. ${ }^{28}$ Given that returns are so volatile on an annual basis but costs are stable, it is difficult to imagine that one would be able to find significant relations between costs and returns in the short run, or, for that matter, between returns in subsequent years. On an annual basis, returns in year $t+1$ will fluctuate a great deal in relation to returns in a year $t$. And given that costs do not fluctuate much, it cannot be expected that there is much of a relation between costs and returns in the short run either, as is also verified in section 5. On the other hand, costs are very persistent, i.e. a fund that has high costs one year, will most likely also have high costs in the following years. When accumulating these costs over many years, they will have a negative impact on returns, i.e. the influence of costs on performance will probably only be clear after several years - which is indeed what our results so far have indicated.

\footnotetext{
${ }^{28}$ We obtain similar results if marked-adjusted returns for, for example, a three year period are considered.
} 


\section{Do investors use the information contained by the ratings?}

As mentioned in the introduction to this paper, the atpRating was originally constructed in order for it to be used when Danes, as of January 1, 2005, were given access to freely allocate their savings in the Special Pension Savings Scheme to different mutual funds. As of June 30, 2005, approximately DKK 77 million, or roughly USD 12 million, have been allocated by 4,252 Danes to the different mutual funds available. ${ }^{29}$

When allocating pension savings in the Special Pension Savings Scheme to different mutual funds, the investor has to use an internet-based trading platform. This internet platform shows the list of available mutual funds together with certain characteristics for each fund, such as the historical return of the fund (ar til dato), a description of the riskiness of the investment strategy of the fund (risiko), and so forth. We show a snapshot of the internet trading platform in Figure 7. Most importantly, however, the internet platform also shows the Morningstar Ratings for the funds as well as the atpRatings for the funds. In other words, we know that when investors decide to allocate their funds into different mutual funds, they have seen both the Morningstar Rating and the atpRating for the funds.

Table 8 shows the percentages of pension savings allocated to mutual funds. ${ }^{30}$ The table reveals that investors have a clear bias in favor of choosing high-rated funds. In particular, $53.6 \%$ of savings allocated to funds rated by the atpRating went to funds in rating category $4+5$ (the low-cost funds) versus only $23.8 \%$ to funds in category $1+2$ (the high-cost funds). For savings allocated into funds rated by Morningstar, the tendency is even stronger: 59.7\% of savings went to funds rated $4+5$ (the best-performing funds) versus $12.3 \%$ of savings to funds rated $1+2$ (the worst-performing funds).

We can be even more systematic in our treatment of investor choices. In particular, we can test whether investors have statistically significant biases in favor of higher-rated funds. Table 9 shows the average ratings of funds sorted in quartiles according to the amount of

29 On average, each individual that has allocated between the different funds, has thus allocated approximately DKK 18,000. In other words, the savings in the Special Pension Savings Scheme constitute only a small fraction of the retirement savings of Danes. This, most likely, also explains why so relatively few (4,252 out of the, in total, 2.7 million Danes that have the possibility of allocating funds in the Special Pension Savings Scheme) have chosen to allocate their funds into different mutual funds instead of just leaving their savings in the predefined asset allocation. In other words, if a pension saver does not decide to actively allocate her savings between the different mutual funds, her savings are automatically allocated into a predefined asset allocation.

${ }^{30}$ Notice that not all funds are rated, i.e. the total amount of invested pension savings differ from the total amount allocated to funds that are rated. Missing ratings are caused by the lack of data, suggesting another advantage of the atpRating compared to the Morningstar Rating. For the atpRating, only one year of cost information is required, whereas three years of return history is needed for the Morningstar Rating. 
savings allocated to the funds (in the columns under "Total Investments") and according to the number of investors having invested in the funds (in the columns under "Number of Investors"). First, note that investors can choose from among 201 different funds, of which 146 are rated by both Morningstar and the atpRating. ${ }^{31}$ The numbers in row "Quartile 1", for instance, are thus the average atpRating and Morningstar Ratings for the $146 / 4=36.5 \approx 37$ funds that have received the smallest amounts of inflow (in the columns under "Total Investments") and the numbers in row "Quartile 4" are the average ratings of the 146/4 = 37 funds that have received the largest amounts of inflow. As can be seen, the average rating for funds that have received the smallest amounts of inflow is 2.8 for the atpRating and 3.4 for the Morningstar Rating, while the corresponding average ratings for funds that have received the largest amounts of inflow are 3.4 for the atpRating and 3.9 for Morningstar. In other words, the average ratings of the funds that have received the largest inflows are higher than the ratings of the funds that have received the least inflow. In more detail, the differences in average ratings between the funds that have received the lowest amount and the highest amount are 0.54 (atpRating) and 0.57 (Morningstar), and these differences are statistically significantly different from zero, as can be seen in the row "p-value". The same pattern of choosing high-rated funds can be observed when considering the number of investors that have invested in the funds as the sorting criteria.

As a robustness check, the same kind of calculations can be made for all the funds that have an atpRating. There are 172 of such funds. The average atpRating for the $25 \%$ of the funds that have received the largest amounts of inflow is 3.32, whereas it is only 2.90 for the $25 \%$ of the funds that have received the smallest inflow; a difference that is significant at the $1 \%$ level.

In summary, we find strong evidence that investors seem to prefer investing in high-rated funds. We also find that investors pay attention to both ratings, as they choose funds that have been rated high by both the atpRating and the Morningstar Rating (remember here that Table 7 shows that the ratings contain different information, i.e. the fact that investors choose funds that are rated high by both the atpRating and the Morningstar Rating is not obvious as the two ratings often pick out different funds as the "best performing" funds as explained in section 6).

31 This number differs from the number of Danish mutual funds that we have been examined so far in this paper. The reason is that only some of the Danish mutual funds are available to Special Pension Savings Scheme investors. 
Our results line up well with those of Guercio \& Tkac (2001), who report that US funds receiving four or five stars from Morningstar have strong inflows. ${ }^{32}$ We report a similar finding for Danish mutual funds and show that the influence of ratings on investor behavior is not a unique feature of Morningstar Ratings, as the investors we study also choose funds that are highly rated by the atpRating.

\section{Conclusion}

In this paper, we have described and analyzed a cost-based indicator of Danish mutual funds. We use the indicator to sort funds, inspired by the Morningstar star ratings, into five different rating categories giving five crowns to the funds with the lowest costs and one crown to the funds with the highest costs.

The development of a cost-based atpRating is based on the idea that costs matter for the after-cost return to the investor, and, at the same time, that costs are considerably more persistent than are returns (that are used by, e.g. Morningstar Ratings). Consequently, we test whether the rating of funds, as based on their costs, provide information about future risk-adjusted excess returns. We find that the cost rating has some predictive power for eight or ten-year out-of-sample long-horizon returns. For example, if the investor in 1994 had invested in the $10 \%$ of funds that had the lowest costs within their ATP-category, she would over the 1994-2003 period have obtained an annual extra 3-4\% of risk-adjusted excess returns as compared to investing in the $10 \%$ of funds that had the highest costs within their ATPcategory.

We also find, in accordance with the results of Guercio \& Tkac (2001), that investors do in fact pay attention to the atpRating, as well as the Morningstar Rating. The data we use here has a unique feature in that we know that the subgroup of investors who have made active investment decisions have been exposed to both the Morningstar and the atpRating. Using data on what mutual funds these investors in fact have chosen, we find that investors mainly allocate savings to funds that have been highly rated by the atpRating or the Morningstar rating. Ratings thus seem to have the potential to affect investor decisions.

We have described a cost-based rating of Danish mutual funds. Given that there are indications that the rating does predict the future performance of some Danish mutual funds

\footnotetext{
${ }^{32}$ Guercio \& Tkac (2001) report that a fund that receives a five-star rating by Morningstar the first time the fund is rated gets a $53 \%$ above normal inflow and that an upgrade from being a four-star fund to a five-star fund generates inflows that are $35 \%$ higher than normally expected flows.
} 
on long horizons, it would be valuable to evaluate how a cost-based rating performs in a market where there are more mutual funds with long histories on costs and performances, as for instance, in the US market. We leave this for future research.

\section{References}

Baker, M., L. Litov, J. Wachter, and J. Wurgler (2005): “Can mutual fund managers pick stocks? Evidence from their trades prior to earnings announcements", manuscript, Wharton School of Business.

Barber, B. B., T. Odean, and L. Zheng (2003): "Out of sight, out of mind: The effects of expenses on mutual fund flows", forthcoming, Journal of Business.

Blake, C. R., E. J. Elton, and M.J. Gruber (1993): "The performance of bond mutual funds", Journal of Business, 6, 57-77.

Blake, C. R. and M. R. Morey (2000): “Morningstar Ratings and mutual fund performance”, Journal of Financial and Quantitative Analysis, 35(3), 451-483.

Carhart, M. M. (1997): “On persistence in mutual fund performance”, Journal of Finance, 52(1), 57-82.

Christensen, M. (2003): “Evaluating Danish mutual fund performance", manuscript, Aarhus School of Business.

Christensen, M. (2005): “Danish mutual fund performance - selectivity, market timing and persistence. Working Paper F-2005-01, Finance Research Group, Aarhus School of Business

Dahlquist, M., S. Engström, and P. Söderling (2000): "Performance and characteristics of Swedish mutual funds", Journal of Financial and Quantitative Analysis, 35(3), 409-423.

Goetzmann, W.N. \& P. Jorion (1999): “Global stock markets in the twentieth century”, Journal of Finance, 54(3), 953-980

Gruber, M.J. (1996): "Another puzzle: The growth in actively managed mutual funds", Journal of Finance, 51(2), 783-810.

Guercio, D. D. \& P. A. Tkac (2001): “Star Power: The effect of Morningstar Ratings on mutual fund flows", Working Paper 2001-15, Federal Reserve Bank of Atlanta.

Holland, P.W. and R.E. Welsch (1977): "Robust regression using iteratively reweighted leastsquares", Communications in Statistics: Theory and Methods, A6, 813-827.

Kosowski, R., A. Timmermann, R. Wermers, \& H. White (2005): "Can mutual fund stars really pick stocks? New evidence from a bootstrap analysis". AFA 2002 Atlanta Meetings; University of Maryland Working Paper. http://ssrn.com/abstract=414441. 
Morey, M. R. (2002): "Rating the raters: An investigation of mutual fund rating services", Journal of Investment Consulting, 5(2), 30-50.

Morningstar (2003): “Denmark cheaper than Europe (In Danish: Billigere end Europa)". Downloadable from http:/ / www.morningstar.dk/news/commentary.asp?

ArticleID=26029\&validfrom $=2003-08-11$

Vinod, H.D. \& M. R. Morey (2002): “Estimation risk in Morningstar mutual fund ratings", Journal of Investing, Winter 2002, 67-75.

Wermers, R. (2000): "Mutual fund performance: An empirical decomposition into stockpicking talent, style, transactions costs, and expenses", Journal of Finance, 55(3), 1655-1695. 
Appendix A.

ATP-categories:

\begin{tabular}{|c|c|c|c|c|c|c|c|}
\hline $\begin{array}{c}\text { ATP- } \\
\text { category }\end{array}$ & Morningstar Category & $\begin{array}{l}\text { ategory } \\
\text { no. }\end{array}$ & Mean (\%) & Median (\%) & Min (\%) & $\operatorname{Max}(\%)$ & Stdev \\
\hline $\mathrm{T}$ & Denmark - Stocks & 119 & 0.9895 & 1.4619 & -14.1690 & 11.3310 & 4.6671 \\
\hline II & Global Large Cap - Stocks & 24 & 0.4431 & 0.8690 & -13.1320 & 11.6100 & 4.7705 \\
\hline II & Global Mid/Small Cap - Stocks & 25 & 0.6778 & 0.7258 & -13.8400 & 14.1020 & 5.0177 \\
\hline III & England Large Cap - Stocks & 1 & 0.5404 & 1.1027 & -10.8850 & 9.1457 & 4.4400 \\
\hline III & Europe ex. England - Stocks & 4 & 0.8252 & 1.3011 & -16.0750 & 14.2700 & 5.4392 \\
\hline III & Euroland Large Cap - Stocks & 6 & 0.7540 & 1.2834 & -16.0940 & 12.8550 & 5.4264 \\
\hline III & Europe Large Cap - Stocks & 9 & 0.6437 & 1.3738 & -13.5970 & 11.4280 & 4.9037 \\
\hline III & Europe Mid Cap - Stocks & 10 & 0.9647 & 1.3495 & -18.3470 & 21.8340 & 5.8127 \\
\hline III & North America Large Cap - Stocks & 13 & 0.7300 & 0.9621 & -13.5030 & 13.5450 & 5.3462 \\
\hline III & North America Mid/Small Cap - Stocks & 14 & 0.9785 & 0.8016 & -17.7740 & 16.1590 & 6.3387 \\
\hline III & Japan Large Cap - Stocks & 17 & -0.0204 & -0.0866 & -13.9150 & 16.3790 & 6.2310 \\
\hline III & Japan Mid/Small Cap - Stocks & 18 & 0.3647 & -0.3531 & -15.6390 & 27.8360 & 7.7124 \\
\hline III & Global New Markets - Stocks & 29 & 0.2287 & 0.6698 & -28.3080 & 16.9230 & 7.1553 \\
\hline IV & DKK Short - Bonds & 121 & 0.3855 & 0.4494 & -0.9886 & 1.2181 & 0.3865 \\
\hline IV & Euro Money market, dynamic & 141 & 0.2793 & 0.2525 & -0.3773 & 1.1840 & 0.2256 \\
\hline $\mathrm{V}$ & EUR Others - Bonds & 66 & 0.4350 & 0.5511 & -1.6654 & 2.1873 & 0.8043 \\
\hline V & DKK Others - Bonds & 120 & 0.4969 & 0.7563 & -3.1244 & 2.9870 & 1.0001 \\
\hline V & DKK Index Bonds & 142 & 0.2607 & 0.3400 & -6.7994 & 6.2084 & 1.6795 \\
\hline $\mathrm{VI}$ & EUR Global - Bonds & 62 & 0.3567 & 0.3276 & -2.3027 & 3.8352 & 1.2720 \\
\hline VI & European - Bonds & 65 & 0.4312 & 0.4931 & -2.3258 & 2.8653 & 1.0525 \\
\hline VII & England Small Cap - Stocks & 3 & 1.0741 & 1.7364 & -19.4530 & 17.7850 & 5.8362 \\
\hline VII & Europe Small Cap - Stocks & 11 & 0.9047 & 1.2636 & -19.0530 & 25.7180 & 6.9256 \\
\hline VII & Asia ex. Japan - Stocks & 20 & 0.2237 & -0.0920 & -24.6290 & 20.0610 & 7.3805 \\
\hline VII & Asia - Stocks & 22 & 0.1434 & -0.5752 & -17.4450 & 15.9820 & 6.0001 \\
\hline VII & Latin-American - Stocks & 23 & 0.6308 & 2.2666 & -34.9740 & 21.5370 & 8.8389 \\
\hline VII & Tech Media Tele - Stocks & 30 & 0.9289 & 0.6618 & -23.7790 & 27.5400 & 8.8879 \\
\hline VII & Natural resources - Stocks & 31 & 0.2639 & 0.3883 & -17.6740 & 17.5580 & 5.2486 \\
\hline VII & Real estate - Stocks & 32 & 0.6706 & 0.6419 & -8.3652 & 6.3508 & 2.9007 \\
\hline VII & Finance - Stocks & 33 & 0.8777 & 1.3684 & -17.7370 & 11.3630 & 5.1242 \\
\hline VII & Health - Stocks & 34 & 1.0106 & 1.0124 & -13.1120 & 10.9560 & 5.3053 \\
\hline VII & Other sectors - Stocks & 35 & 0.5094 & 0.7534 & -13.0590 & 10.1110 & 4.2899 \\
\hline VII & Switzerland - Stocks & 105 & 0.6501 & 1.0045 & -16.2180 & 11.0370 & 4.8464 \\
\hline VII & Nordic countries - Stocks & 107 & 0.9506 & 1.1465 & -17.9650 & 20.3520 & 6.2114 \\
\hline VII & Central- and Eastern Europe - Stocks & 110 & 1.1339 & 1.8561 & -38.3660 & 24.4430 & 8.5835 \\
\hline VIII & EUR Low Risk - Balanced & 36 & 0.3512 & 0.3978 & -2.1678 & 2.5974 & 1.0370 \\
\hline VIII & EUR Moderate Risk - Balanced & 37 & 0.4094 & 0.7512 & -6.2787 & 5.8262 & 2.3777 \\
\hline VIII & EUR High Risk - Balanced & 38 & 0.4465 & 0.8031 & -9.2073 & 7.8733 & 3.3809 \\
\hline VIII & USD - Balanced & 43 & 0.3860 & 0.7875 & -7.9699 & 8.7047 & 3.2857 \\
\hline VIII & USD - Money market & 50 & 0.2460 & 0.0135 & -6.7711 & 6.6643 & 2.7158 \\
\hline VIII & GBP Govn. - Bonds & 56 & 0.5690 & 0.6594 & -5.6330 & 6.6641 & 2.3792 \\
\hline VIII & EUR High yield - Bonds & 58 & 0.2157 & 0.5020 & -7.4638 & 5.5913 & 1.8733 \\
\hline VIII & USD High yield - Bonds & 60 & 0.5587 & 0.6893 & -8.9057 & 8.6573 & 3.4237 \\
\hline VIII & New markets - Bonds & 61 & 0.8205 & 1.1250 & -11.7030 & 10.1340 & 3.4096 \\
\hline VIII & GBP Global - Bonds & 63 & 0.4729 & 0.5415 & -2.7124 & 4.4158 & 1.7199 \\
\hline VIII & USD Global - Bonds & 64 & 0.2955 & 0.0823 & -4.3036 & 5.1672 & 1.8509 \\
\hline VIII & GBP Others - Bonds & 67 & 0.4935 & 0.5417 & -5.9587 & 7.0904 & 2.4799 \\
\hline VIII & USD Others - Bonds & 68 & 0.3938 & 0.2785 & -5.3368 & 7.4308 & 2.5529 \\
\hline VIII & Guaranteed funds & 69 & 0.4183 & 0.3462 & -2.2095 & 2.5699 & 0.9998 \\
\hline VIII & NOK Others - Bonds & 109 & 0.4828 & 0.4393 & -6.9504 & 7.3401 & 1.8993 \\
\hline VIII & SEK Others - Bonds & 118 & 0.4992 & 0.3571 & -8.6444 & 8.2001 & 2.2249 \\
\hline
\end{tabular}

I: Danish Stocks, II: Global Stocks, III: Regional Stocks,

IV: Short Bonds, V: Long Bonds, VI: Global Bonds,

VII: Other Stocks, and VIII: Other Bonds

The table shows classifications of Morningstar Categories into ATP-categories. The table furthermore shows summary statistics (mean, median, maximum, minimum, and standard deviations) of the monthly returns to the funds in the categories. 
Table 1. Costs in different categorizes of Danish mutual funds. 2003.

\begin{tabular}{clrrrrrrrr}
\hline & \multicolumn{4}{c}{ Stocks } & \multicolumn{5}{c}{ Bonds } \\
\hline & Danish & \multicolumn{1}{c}{ Global } & Regional & Others & Short & Long & Global & Others \\
\hline \multirow{5}{*}{ Ope. costs } & Average & 1.19 & 1.36 & 1.13 & 1.47 & 0.67 & 0.60 & 0.85 & 1.00 \\
& Median & 1.03 & 1.32 & 1.24 & 1.42 & 0.55 & 0.55 & 0.72 & 0.99 \\
& Minimum & 0.48 & 0.27 & 0.39 & 0.73 & 0.11 & 0.15 & 0.22 & 0.12 \\
& Maximum & 2.09 & 3.39 & 3.35 & 2.64 & 2.00 & 1.10 & 3.08 & 2.15 \\
& Average & 1.97 & 2.14 & 1.70 & 2.38 & 0.82 & 1.03 & 1.37 & 1.85 \\
Front-end fee & Median & 2.10 & 2.35 & 2.03 & 2.37 & 0.89 & 1.22 & 1.45 & 1.98 \\
& Minimum & 0.25 & 0.50 & 0.25 & 0.40 & 0.00 & 0.00 & 0.30 & 0.20 \\
& Maximum & 2.61 & 3.00 & 3.00 & 3.50 & 1.50 & 1.75 & 1.75 & 2.91 \\
& Average & 0.70 & 0.78 & 0.75 & 0.96 & 0.22 & 0.21 & 0.34 & 0.52 \\
Back-end fee & Median & 0.75 & 0.85 & 0.75 & 0.90 & 0.14 & 0.15 & 0.30 & 0.50 \\
& Minimum & 0.20 & 0.20 & 0.25 & 0.38 & 0.00 & 0.03 & 0.15 & 0.00 \\
& Maximum & 1.36 & 1.50 & 1.60 & 1.75 & 0.75 & 0.92 & 1.00 & 1.75 \\
\hline
\end{tabular}

This table shows summary statistics of the operating costs for 2003, the front-end load fees for 2003, and back-end load fees for 2003. We have divided the individual mutual funds into four bond categories and four equity categories. For each category of mutual funds, we provide the average cost, the median cost, and the minimum and maximum costs that a mutual fund within the category has charged.

Table 2. Annual returns from investing in mutual funds with low and high costs.

\begin{tabular}{|c|c|c|c|c|c|c|c|c|c|c|}
\hline & & & & Stoc & $k s$ & & & Bor & & \\
\hline & $\overline{\text { Year }}$ & costs & Danish & Global & Regional & Others & Short & Long & Global & Others \\
\hline & 1 & Low & $11.02 \%$ & $10.95 \%$ & $11.05 \%$ & $10.41 \%$ & $6.89 \%$ & $6.82 \%$ & $6.30 \%$ & $6.67 \%$ \\
\hline Q & 1 & High & $5.66 \%$ & $3.86 \%$ & $3.80 \%$ & $3.81 \%$ & $2.67 \%$ & $3.12 \%$ & $1.11 \%$ & $0.10 \%$ \\
\hline 힐 & 5 & Low & $11.42 \%$ & $11.57 \%$ & $11.50 \%$ & $11.10 \%$ & $6.89 \%$ & $6.84 \%$ & $6.68 \%$ & $6.84 \%$ \\
\hline むు & 5 & High & $9.05 \%$ & $7.64 \%$ & $7.66 \%$ & $8.23 \%$ & $4.53 \%$ & $5.34 \%$ & $3.35 \%$ & $3.88 \%$ \\
\hline तె & 11 & Low & $11.47 \%$ & $11.65 \%$ & $11.56 \%$ & $11.18 \%$ & $6.89 \%$ & $6.85 \%$ & $6.73 \%$ & $6.86 \%$ \\
\hline ગ & 10 & High & $9.48 \%$ & $8.13 \%$ & $8.15 \%$ & $8.79 \%$ & $4.76 \%$ & $5.62 \%$ & $3.64 \%$ & $4.37 \%$ \\
\hline 产 & & Low & $11.49 \%$ & $11.69 \%$ & $11.58 \%$ & $11.23 \%$ & $6.89 \%$ & $6.85 \%$ & $6.76 \%$ & $6.87 \%$ \\
\hline & 20 & High & $9.69 \%$ & $8.37 \%$ & $8.40 \%$ & $9.08 \%$ & $4.88 \%$ & $5.76 \%$ & $3.78 \%$ & $4.61 \%$ \\
\hline & 1 & Low & $92 \%$ & $91 \%$ & $92 \%$ & $87 \%$ & $98 \%$ & $97 \%$ & $90 \%$ & $95 \%$ \\
\hline & 1 & High & $47 \%$ & $32 \%$ & $32 \%$ & $32 \%$ & $38 \%$ & $45 \%$ & $16 \%$ & $1 \%$ \\
\hline & 5 & Low & $95 \%$ & $96 \%$ & $96 \%$ & $92 \%$ & $98 \%$ & $98 \%$ & $95 \%$ & $98 \%$ \\
\hline 웜 & 5 & High & $75 \%$ & $64 \%$ & $64 \%$ & $69 \%$ & $65 \%$ & $76 \%$ & $48 \%$ & $55 \%$ \\
\hline 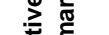 & 10 & Low & $96 \%$ & $97 \%$ & $96 \%$ & $93 \%$ & $98 \%$ & $98 \%$ & $96 \%$ & $98 \%$ \\
\hline & 10 & High & $79 \%$ & $68 \%$ & $68 \%$ & $73 \%$ & $68 \%$ & $80 \%$ & $52 \%$ & $62 \%$ \\
\hline & 20 & Low & $96 \%$ & $97 \%$ & $97 \%$ & $94 \%$ & $98 \%$ & $98 \%$ & $97 \%$ & $98 \%$ \\
\hline & 20 & High & $81 \%$ & $70 \%$ & $70 \%$ & $76 \%$ & $70 \%$ & $82 \%$ & $54 \%$ & $66 \%$ \\
\hline & 1 & Low & $51 \%$ & $74 \%$ & $58 \%$ & $54 \%$ & $0 \%$ & $18 \%$ & $69 \%$ & $64 \%$ \\
\hline & 1 & High & $67 \%$ & $59 \%$ & $60 \%$ & $68 \%$ & $54 \%$ & $72 \%$ & $49 \%$ & $70 \%$ \\
\hline d 용 & 5 & Low & $17 \%$ & $35 \%$ & $22 \%$ & $19 \%$ & $0 \%$ & $4 \%$ & $30 \%$ & $26 \%$ \\
\hline ¿ & 5 & High & $28 \%$ & $22 \%$ & $22 \%$ & $29 \%$ & $19 \%$ & $34 \%$ & $16 \%$ & $31 \%$ \\
\hline ర్ ర్ శ్రు & 10 & Low & $9 \%$ & $21 \%$ & $12 \%$ & $10 \%$ & $0 \%$ & $2 \%$ & $18 \%$ & $15 \%$ \\
\hline 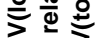 & 10 & High & $16 \%$ & $12 \%$ & $12 \%$ & $17 \%$ & $11 \%$ & $21 \%$ & $9 \%$ & $19 \%$ \\
\hline & & Low & $5 \%$ & $11 \%$ & $7 \%$ & $6 \%$ & $0 \%$ & $1 \%$ & $10 \%$ & $8 \%$ \\
\hline & 20 & High & $9 \%$ & $6 \%$ & $7 \%$ & $9 \%$ & $6 \%$ & $12 \%$ & $5 \%$ & $11 \%$ \\
\hline
\end{tabular}

This table shows the annual returns and the returns relative to the market that will be realized when investing in mutual funds with low and high costs respectively for different investment horizons. Low (high) costs are defined as minimum (maximum) costs within a category. Percentages refer to the return the investor gets from investing in mutual funds compared to the return the stock, respectively the bond, market generates. Finally, the table also shows the present value of the load fees that will be paid relative to the present value of all costs associated with the investment. 
Table 3. Numbers of funds in different ATP-categories.

\begin{tabular}{l|ccccccccr}
\hline & \multicolumn{9}{|c}{ Stocks } \\
\hline & Danish & Global & Regional & Others & Short & Long & Global & Other & Total \\
\hline 3 years & 28 & 35 & 50 & 60 & 21 & 43 & 12 & 19 & 268 \\
5 years & 21 & 17 & 28 & 34 & 15 & 26 & - & - & 141 \\
8 years & 12 & 16 & 17 & 17 & - & 14 & - & - & 76 \\
10 years & - & 14 & 17 & - & - & 11 & - & - & 42 \\
\hline
\end{tabular}

This table shows the number of Danish mutual funds in each mutual fund category when the period to be analyzed spans 3 years (the 2001-2003 period), 5 years (the 1999-2003 period), 8 years (the 19962003 period), and 10 years (the 1994-2003 period). The table shows the number of funds in categories where there are at least ten funds. If there are less than ten funds in a category, the funds in the category are not rated in the atpRating. In the table, a dash indicates that there are less than ten funds in the particular category.

Table 4. Sensitivity of fund ratings to the choice of weights in the cost indicator, 2003.

\begin{tabular}{rrrrrr}
\hline & $\mathbf{1}$ & $\mathbf{2}$ & $\mathbf{3}$ & $\mathbf{4}$ & $\mathbf{5}$ \\
\hline $\mathbf{1}$ & 25 & 9 & 2 & 0 & 0 \\
$\mathbf{2}$ & 10 & 39 & 25 & 2 & 0 \\
$\mathbf{3}$ & 1 & 26 & 76 & 16 & 0 \\
$\mathbf{4}$ & 0 & 2 & 15 & 46 & 11 \\
$\mathbf{5}$ & 0 & 0 & 2 & 6 & 30 \\
\hline
\end{tabular}

This table shows a transition matrix of the sensitivity of the classification of funds in 2003 into different atpRating categories when changing the weight on operating costs from 0.7 to 0.9 . For instance, the first row shows that 25 funds were ranked into atpRating category 1 regardless of whether the weight on operating expenses was 0.7 or 0.9 . The nine funds that were initially rated in category 1 when the weight was 0.7 , changed to category 2 when the weight was changed to 0.9 , and 2 funds changed from category 1 to category 3 as a consequence of the change in the weight on operating costs from 0.7 to 0.9 .

Table 5. Mean and median alphas for funds in different atpRating categories.

\begin{tabular}{|c|c|c|c|c|c|c|c|c|}
\hline \multicolumn{3}{|c|}{3 years } & \multicolumn{2}{|l|}{5 years } & \multicolumn{2}{|l|}{8 years } & \multicolumn{2}{|l|}{10 years } \\
\hline atpRating & Mean & Median & Mean & Median & Mean & Median & Mean & Median \\
\hline 1 & 0.14 & -0.02 & 0.19 & 0.09 & 0.04 & -0.04 & -0.13 & -0.13 \\
\hline 2 & 0.12 & 0.02 & 0.06 & 0.00 & -0.01 & -0.03 & 0.00 & 0.00 \\
\hline 3 & -0.10 & -0.09 & -0.02 & -0.03 & -0.04 & -0.04 & -0.07 & 0.01 \\
\hline 4 & -0.01 & 0.01 & -0.06 & -0.05 & -0.08 & -0.01 & 0.03 & -0.01 \\
\hline 5 & 0.08 & 0.03 & 0.19 & 0.02 & 0.29 & 0.18 & 0.20 & 0.19 \\
\hline $5-1$ & -0.06 & 0.05 & 0.01 & -0.06 & 0.25 & 0.22 & 0.33 & 0.32 \\
\hline$p$-value & 0.34 & & 0.49 & & 0.10 & & 0.01 & \\
\hline$(4+5)-(2+1)$ & -0.10 & 0.00 & -0.08 & -0.02 & 0.03 & 0.06 & 0.11 & 0.11 \\
\hline $\mathrm{p}$-value & 0.07 & & 0.14 & & 0.37 & & 0.05 & \\
\hline
\end{tabular}

This table shows the mean and median alphas for funds in different atpRating categories for different investment periods: 3 years, 5 years, 8 years, and 10 years. In row " $5-1$ ", the differences in median and mean alphas for funds in atpRating category 5, respectively, 1 are shown, and in the "p-value" row below, the p-values from t-tests of whether the means are significantly different are shown. In row " $(4+5)-(2+1)$, the differences in median and mean alphas for funds in atpRating categories $4+5$ and $1+2$ are shown, and in the "p-value" row below, the p-values for t-tests of whether the means are significantly different are shown. 
Table 6. Dummy variable regression. All funds.

\begin{tabular}{|c|c|c|c|c|c|c|c|c|c|c|c|c|c|}
\hline & Obs & $\begin{array}{l}\text { Adj. } \\
R^{2}\end{array}$ & $\begin{array}{c}p- \\
\text { value } \\
\text { F-test }\end{array}$ & $\begin{array}{c}\delta_{1} \\
\text { Cons. }\end{array}$ & $p$-value & $\begin{array}{c}\delta_{2} \\
\text { Rat } 2\end{array}$ & $p$-value & $\begin{array}{c}\delta_{3} \\
\text { Rat } 3\end{array}$ & $p$-value & $\begin{array}{c}\delta_{4} \\
\text { Rat 4 }\end{array}$ & $p$-value & $\begin{array}{c}\delta_{5} \\
\text { Rat } 5\end{array}$ & $p$-value \\
\hline 3 year, OLS & 268 & 0.077 & $0 \%$ & 0.213 & $0 \%$ & -0.108 & $22 \%$ & -0.323 & $0 \%$ & -0.229 & $1 \%$ & -0.127 & $22 \%$ \\
\hline 3 year, Robust & & & & -0.026 & $56 \%$ & 0.053 & $33 \%$ & -0.074 & $15 \%$ & -0.007 & $90 \%$ & 0.022 & $73 \%$ \\
\hline 5 year, OLS & 141 & 0.051 & $13 \%$ & 0.152 & $6 \%$ & -0.144 & $14 \%$ & -0.156 & $9 \%$ & -0.160 & $10 \%$ & 0.032 & $78 \%$ \\
\hline 5 year, Robust & & & & -0.010 & $86 \%$ & -0.033 & $63 \%$ & -0.021 & $74 \%$ & -0.043 & $53 \%$ & 0.045 & $58 \%$ \\
\hline 8 year, OLS & 76 & 0.163 & $1 \%$ & -0.008 & $92 \%$ & 0.010 & $92 \%$ & -0.032 & $74 \%$ & -0.064 & $53 \%$ & 0.295 & $2 \%$ \\
\hline 8 year, Robust & & & & -0.103 & $14 \%$ & 0.067 & $42 \%$ & 0.046 & $56 \%$ & 0.055 & $50 \%$ & 0.248 & $1 \%$ \\
\hline 10 year, OLS & 42 & 0.193 & $9 \%$ & -0.130 & $14 \%$ & 0.110 & $29 \%$ & 0.080 & $43 \%$ & 0.165 & $11 \%$ & 0.326 & $1 \%$ \\
\hline 10 year, Robust & & & & -0.130 & $11 \%$ & 0.064 & $50 \%$ & 0.118 & $21 \%$ & 0.153 & $11 \%$ & 0.322 & $1 \%$ \\
\hline
\end{tabular}

This table shows the results from the regressions of alphas of Danish mutual funds on a dummy variable that picks out funds in atpRating category 2 (the estimated coefficient to the dummy being $\delta_{2}$ ), a dummy that picks out funds in atpRating category 3 (the estimated coefficient being $\delta_{3}$ ), for funds in category 4 (coefficient $\delta_{4}$ ), and for funds in category 5 (with estimated coefficient $\delta_{5}$ ). $\delta_{1}$ is the estimate of the constant. The table shows the estimated coefficients and the associated p-values from ttests of whether the particular coefficient is statistically distinguishable from zero. The coefficients have been estimated using simple OLS techniques and robust estimation techniques that take into account the influence of outliers. Finally, the table shows the number of observations in each regression and the $R^{2} \mathrm{~s}$.

Table 7. The rating of funds by the Morningstar Rating and the atpRating in 2003.

\begin{tabular}{|c|c|c|c|c|c|c|}
\hline & & \multicolumn{5}{|c|}{ atpRating (2003) } \\
\hline & & 1 & 2 & 3 & 4 & 5 \\
\hline \multirow{6}{*}{ MS(2003) } & 1 & $0.0 \%$ & $6.0 \%$ & $5.5 \%$ & $0.0 \%$ & $0.0 \%$ \\
\hline & 2 & $4.2 \%$ & $20.0 \%$ & $20.9 \%$ & $10.7 \%$ & $23.5 \%$ \\
\hline & 3 & $37.5 \%$ & $40.0 \%$ & $48.4 \%$ & $50.0 \%$ & $35.3 \%$ \\
\hline & 4 & $29.2 \%$ & $22.0 \%$ & $17.6 \%$ & $33.9 \%$ & $17.6 \%$ \\
\hline & 5 & $29.2 \%$ & $12.0 \%$ & $7.7 \%$ & $5.4 \%$ & $23.5 \%$ \\
\hline & & $100.0 \%$ & $100.0 \%$ & $100.0 \%$ & $100.0 \%$ & $100.0 \%$ \\
\hline
\end{tabular}

This table shows the relation between the ratings of mutual funds in 2003 by the Morningstar Rating and the atpRating. In each column, the distribution of the funds in a certain atpRating category across the different Morningstar categories is shown. 
Table 8. Savings allocated to mutual funds in different atpRating and Morningstar Rating categories. The first six months of 2005.

\begin{tabular}{l|rrrrrr}
\hline & \multicolumn{1}{|c}{1} & \multicolumn{1}{c}{2} & \multicolumn{1}{c}{3} & \multicolumn{1}{c}{4} & \multicolumn{1}{c}{5} & \multicolumn{1}{c}{ Total } \\
\hline ATP & $8,489,867$ & $8,661,610$ & $16,333,625$ & $27,242,059$ & $11,453,867$ & $72,181,028$ \\
& $11.76 \%$ & $12.00 \%$ & $22.63 \%$ & $37.74 \%$ & $15.87 \%$ & \\
\hline Morningstar & $3,048,738$ & $3,378,093$ & $14,566,649$ & $12,042,375$ & $19,086,653$ & $52,122,508$ \\
& $5.85 \%$ & $6.48 \%$ & $27.95 \%$ & $23.10 \%$ & $36.62 \%$ & \\
\hline
\end{tabular}

This table shows the total value of savings allocated to funds in different rating categories, as well as the percentages of the total values for each rating category. The total amount allocated to funds rated by the atpRating is different from the total amount allocated to funds rated by the Morningstar Rating because the Morningstar Rating needs a longer history of performance data before it can rate funds. Consequently there are some funds that are rated by the atpRating only.

Table 9. Average ratings of mutual funds sorted into quartiles as based on inflows to the funds.

\begin{tabular}{rrrrr}
\hline & \multicolumn{2}{c}{ Total investments } & \multicolumn{2}{c}{ Number of investors } \\
\hline \multicolumn{1}{c}{ Quartile } & atpRating & Morningstar & atpRating & Morningstar \\
\hline 1 & 2.8 & 3.4 & 2.9 & 3.2 \\
2 & 3.0 & 2.9 & 2.9 & 3.2 \\
3 & 3.1 & 3.5 & 3.1 & 3.4 \\
4 & 3.4 & 3.9 & 3.4 & 3.9 \\
& & & & \\
$4-1$ & 0.54 & 0.57 & 0.43 & 0.76 \\
p-value & $2.0 \%$ & $1.6 \%$ & $4.2 \%$ & $0.2 \%$ \\
\hline
\end{tabular}

Table 9 shows the mutual funds sorted into quartiles, as based on the total inflows to the funds from savings in the Special Pension Savings Scheme ("Total investments"), as well as the number of investors having invested in the funds. Quartile 1 has the funds that have received the lowest amounts of inflows (for "Total investments") and the funds that have attracted the smallest numbers of investors (in the columns under "Number of investors"). Quartile 4 has the funds that have attracted the largest amounts of money or the largest number of investors. The table shows the average atpRating and the average Morningstar Rating of the funds in the different quartiles. Row " $4-1$ " shows the differences in average ratings between funds in quartiles 4 and 1, and row "p-value" shows pvalues from one-sided t-tests of whether the differences in row " $4-1$ " are statistically different from zero. 
Figure 1. Number of Danish mutual funds in different categories during the sample period.

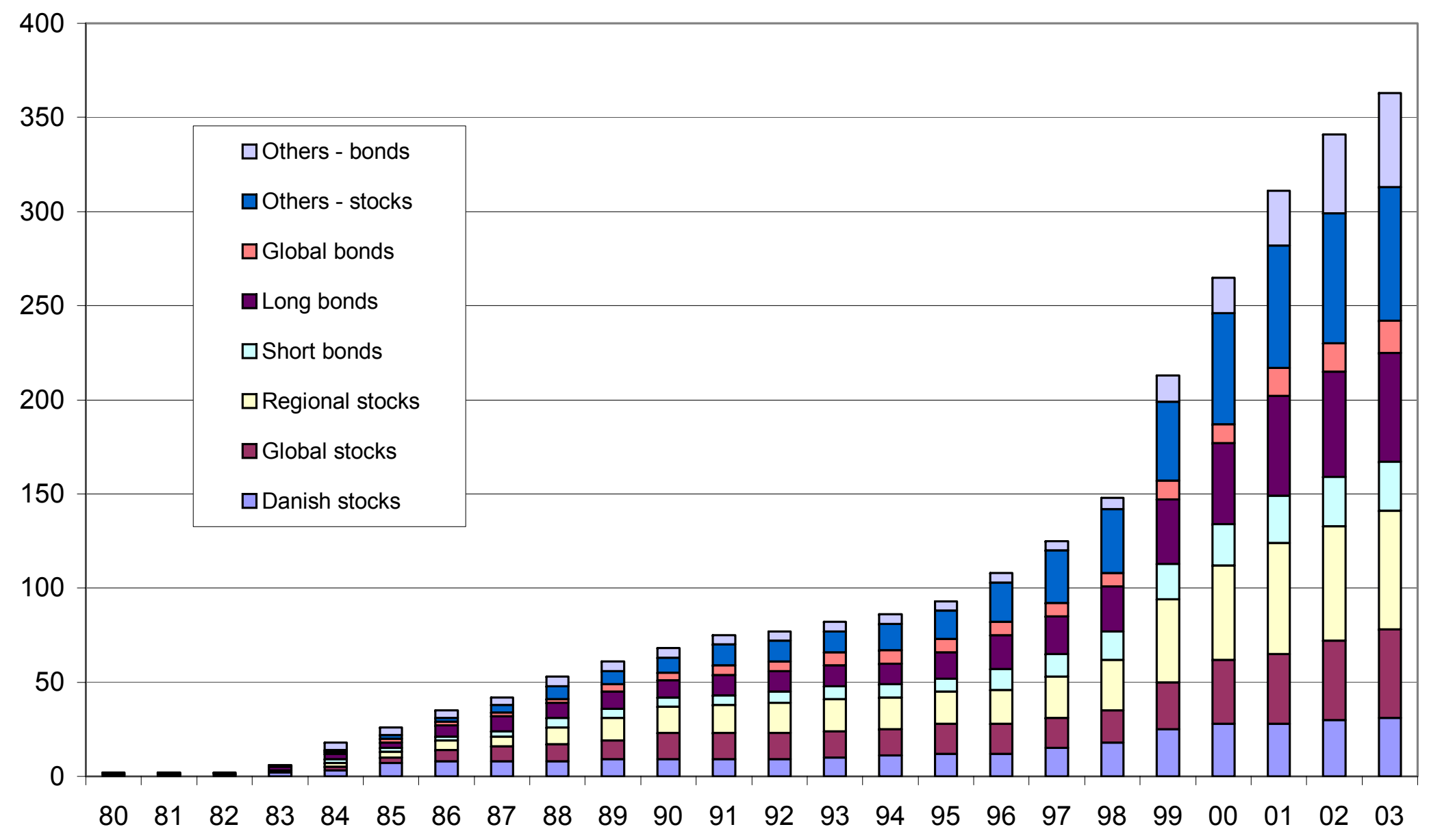


Figure 2. Average operating costs for Danish mutual funds, 1994-2003.

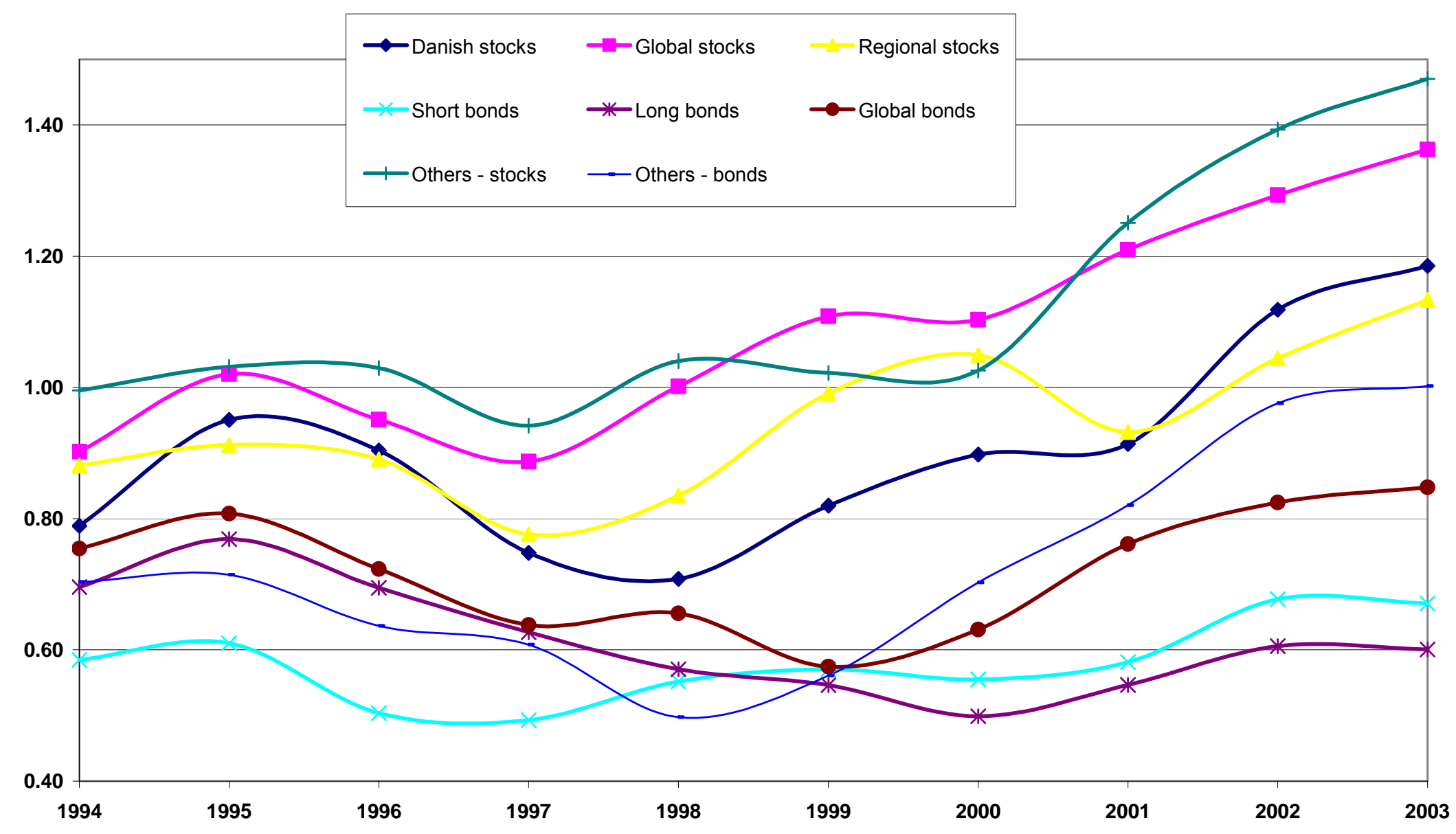


Figure 3. Alphas of the individual funds estimated on the 1994-2003 period against the apRating category of the individual funds in 1994. The alphas measure the average monthly risk-adjusted excess return obtained for the 1994-2003 period.

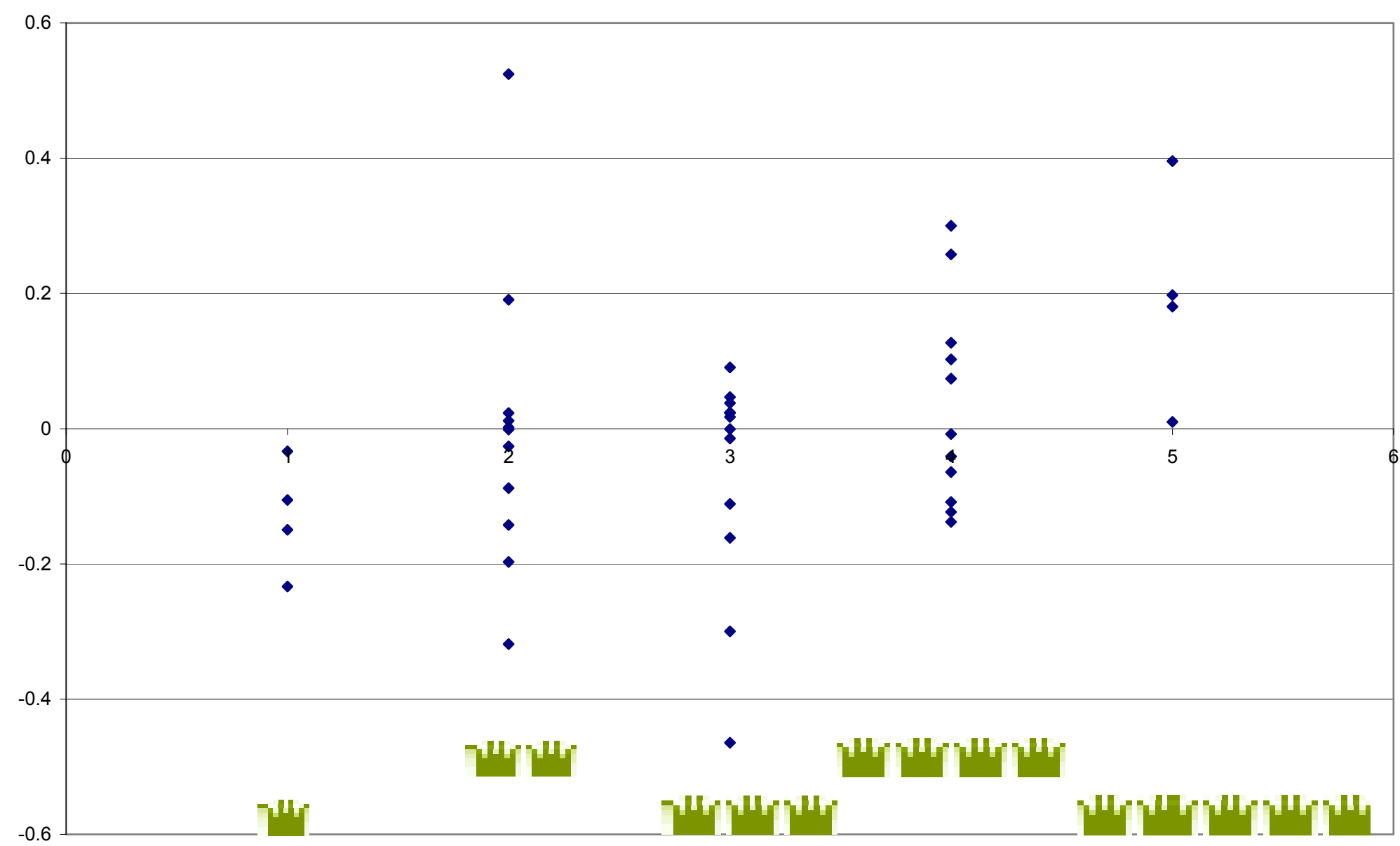


Figure 4. Alphas of the individual funds, estimated on the 2001-2003 period, against the apRating category of the funds in 2000. The alphas measure the average monthly risk-adjusted excess return obtained over the 2001-2003 period.

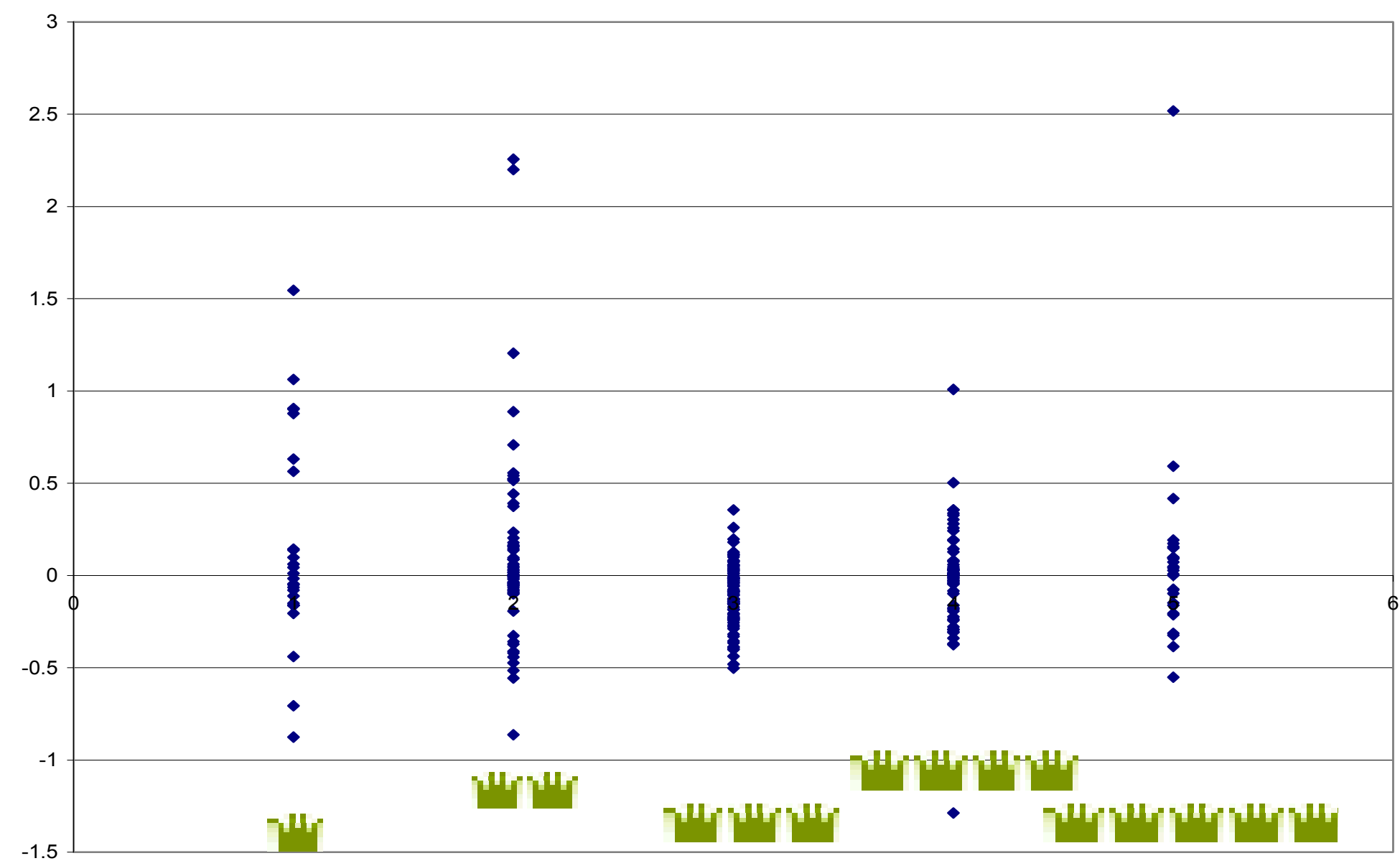


Figure 5. Scatter plot of last year's operating costs against this year's operating costs.

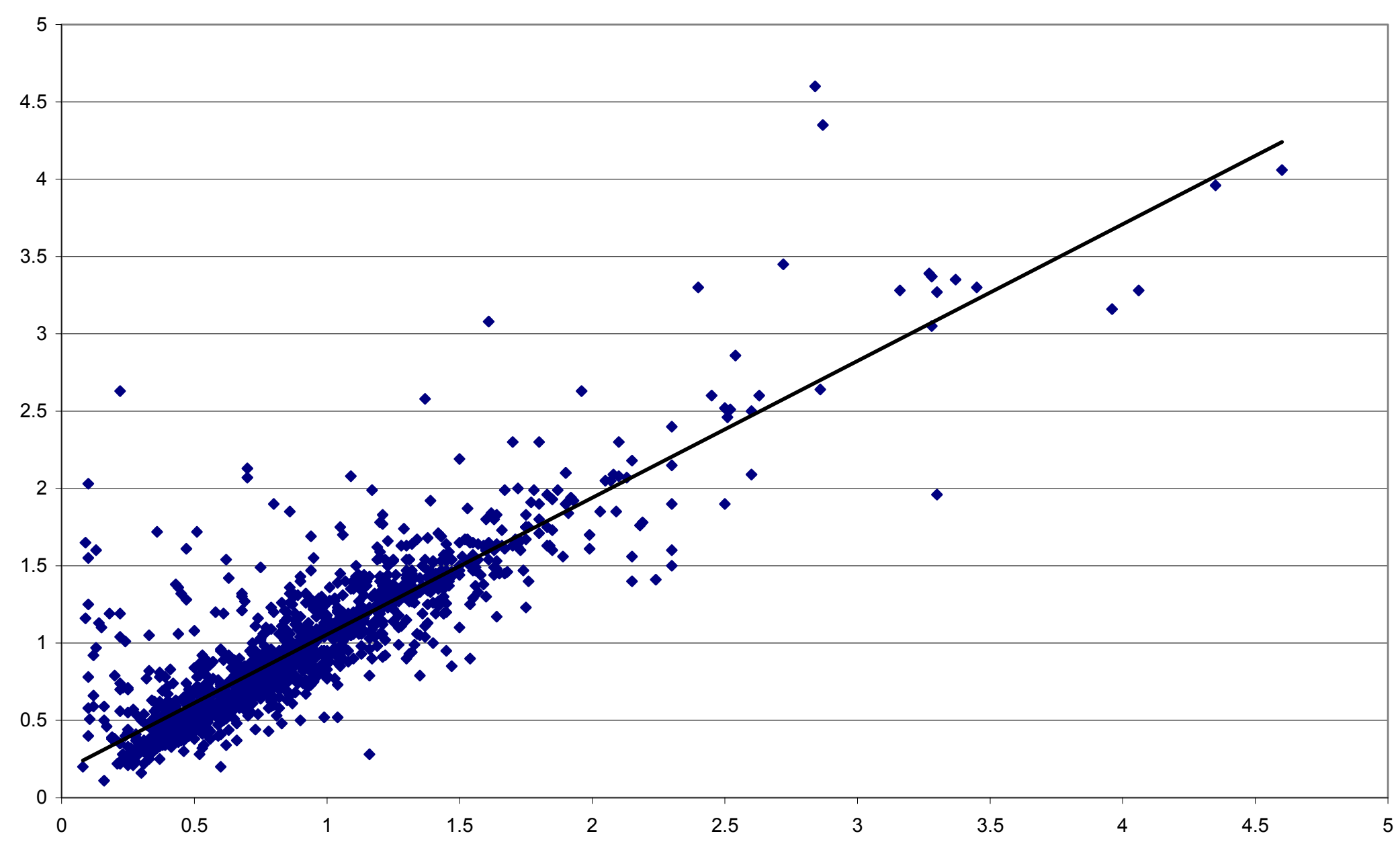


Figure 6. Scatter plot of last year's return against this year's return.

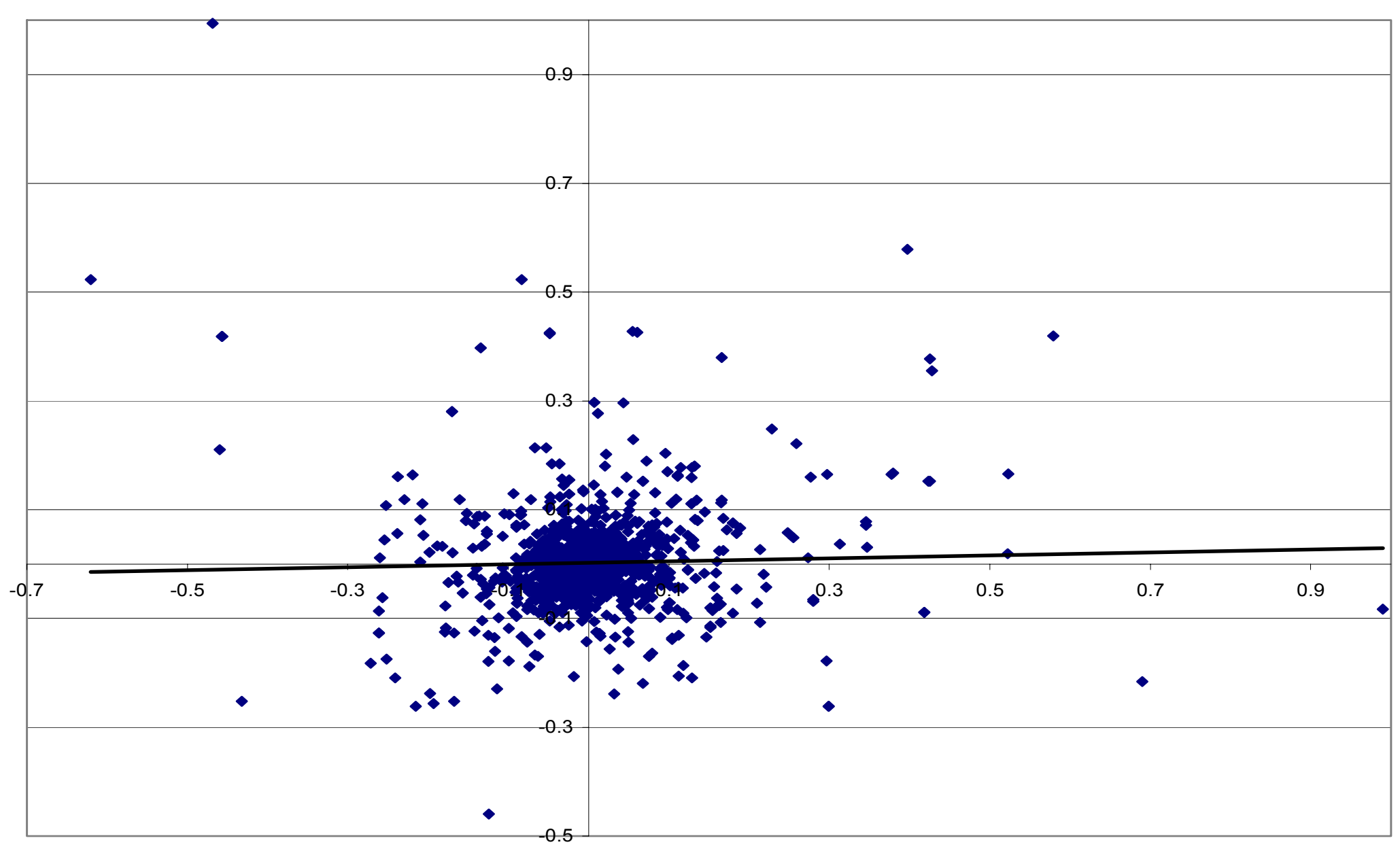


Figure 7. The ATP trading platform.

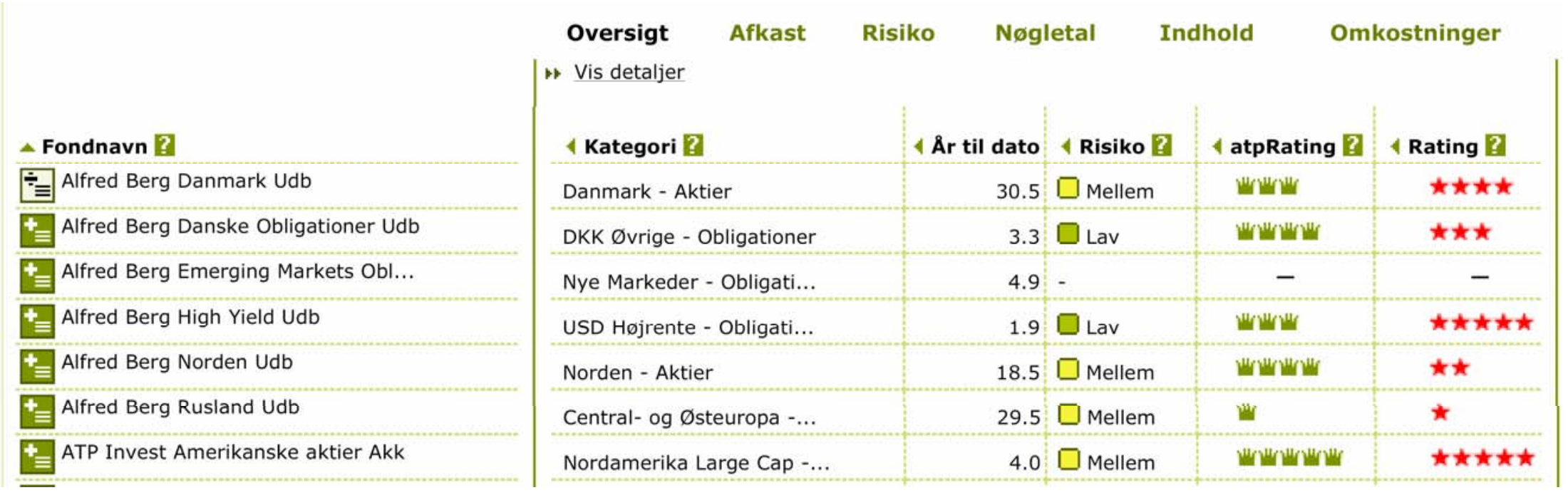


INSTITUT FOR FINANSIERINGs working papers siden 2000:

WP 2000-1 Bjarne Astrup Jensen and Carsten Sørensen: Paying for minimum interest rate guarantees: Who should compensate who?

WP 2000-2 Jan Jakobsen and Ole Sørensen: Decomposing and testing Long-run Returns with an application to initial public offerings in Denmark.

WP 2000-3 Jan Jakobsen and Torben Voetmann: Volatility-Adjusted Performance An Alternative Approach to Interpret Long-Run Returns.

WP 2000-4 Jan Jakobsen and Torben Voetmann: Post-Acquisition Performance in the Short and Long-Run Evidence from the Copenhagen Stock Exchange 1993-1997.

WP 2000-5 Ken L. Bechmann and Johannes Raaballe: A Regulation of Bids for Dual Class Shares. Implication: Two Shares - One Price.

WP 2000-6 Torben Voetmann: Changes in the Bid-Ask Componets Around Earnings Announcemtents: Evidence from the Copenhagen Stock Exchange.

WP 2000-7 Henrik Lando: The Optimal Standard of Proof in Criminal Law When Both Fairness and Deterrence Are Social Aims.

WP 2000-8 Jesper Rangvid and Carsten Sørensen: Convergence in the ERM and Declining Numbers of Common Stochastic Trends.

WP 2000-9 Claus Munk and Carsten Sørensen: Optimal Consumption and Investment Strategies with Stochastic Interest Rates.

WP 2000-10 Henrik Lando and Caspar Rose: On Specific Performance in Civil Law and Enforcement Costs.

WP 2000-11 Henrik Lando: Ny lov om jordforurening i økonomisk belysning.

WP 2001-1 Michael Møller, Claus Parum og Thomas Sørensen: Den ny pensionsafkastbeskatningslov.

WP 2001-2 Bjarne Astrup Jensen: Mean variance efficient portfolios by linear programming: A review of some portfolio selection criteria of Elton, Gruber and Padberg. 
WP 2001-3 Caspar Rose: Impact of Investor Meetings/Presentations on Share Prices, Insider Trading and Securities Regulation.

WP 2001-4 Caspar Rose: Corporate Financial Performance and the Use of Takeover Defenses.

WP 2001-5 Shubhashis Gangopadhyay and Clas Wihlborg: The Impact of Bankruptcy Rules on Risky Project Choice and Skill Formation under Credit Rationing.

WP 2001-6 Claus Munk, Carsten Sørensen \& Tina Nygaard Vinther: Portfolio Choice under Inflation: Are Popular Recommendations Consistent with Rational Behaviour?

WP 2001-7 Ken L. Bechmann: Evidence on the Limits of Arbitrage: Short Sales, Price Pressure, and the Stock Price Response to Convertible Bond Calls.

WP 2001-8 Michael Møller \& Caspar Rose: Legal pre-emption rights as calloptions, redistribution and efficiency loss.

WP 2001-9 Peter Raahauge: Empirical Rationality in the Stock Market.

WP 2002-1 Bjarne Astrup Jensen: On valuation before and after tax in no arbitrage models: Tax neutrality in the discrete time model.

WP 2002-2 Ken L. Bechmann: Price and Volume Effects Associated with Changes in the Danish Blue-Chip Index - The KFX Index.

WP 2002-3 Steen Thomsen and Caspar Rose: Foundation ownership and financial performance. Do companies need owners?

WP 2002-4 Martin Richter and Carsten Sørensen: Stochastic Volatility and Seasonality in Commodity Futures and Options: The Case of Soybeans.

WP 2002-5 Caspar Rose: Aktiemarkedets reaktion på indførelsen af incitamentsprogrammer.

WP 2002-6 Caspar Rose: Impact of Takeover Defenses on Managerial Incentives.

WP 2002-7 Ken L. Bechmann og Peter Løchte Jørgensen: Optionsaflønning i danske børsnoterede selskaber.

WP 2002-8 Jesper Rangvid: Output and Expected Returns - a multicountry study. 
WP 2002-9 Jonas Aziz Bhatti og Michael Møller: Pensionsafkastbeskatning og optimal porteføljesammensætning.

WP 2003-1 Bjarne Florentsen, Michael Møller and Niels Chr. Nielsen: Reimbursement of VAT on written-off Receivables.

WP 2003-2: Ken L. Bechmann and Peter Løchte Jørgensen: The Value and Incentives of Option-based Compensation in Danish Listed Companies.

WP 2004-1 Ken L. Bechmann and Johannes Raaballe: The Difference Between Stock Splits and Stock Dividends - Evidence from Denmark.

WP 2004-2 Caspar Rose: Bestyrelsessammensætning og finansiel performance i danske børsnoterede virksomheder - Er Nørbyrapportens anbefalinger til gavn for aktionærerne?

WP 2004-3 Jens Lunde: Lack of balance in after-tax returns - lack of tenure neutrality. The Danish case.

WP 2004-4 Peter Raahauge: Upper Bounds on Numerical Approximation Errors.

WP 2004-5 Peter Raahauge: Higher-Order Finite Element Solutions of Option Prices.

WP 2004-6 Anders Holst \& Morten Nalholm: Modelling Callable Annuity Bonds with Interest-Only Optionality.

WP 2005-1 Finn Østrup: Fiscal Policy and Welfare under Different Exchange Rate Regimes.

WP 2005-2 Finn Østrup: The Choice of Monetary Regime: Fiscal Implications.

WP 2005-3 Lunde, Jens: The owner-occupiers’ structure during a house price boom - Does negative equity exist as a permanent feature in the Danish housing market?

WP 2005-4 Ken L. Bechmann and Johannes Raaballe: Taxable Cash Dividends - A Useful Way of Burning Money. 
WP 2005-5 Bjarne Astrup Jensen, Fredrik Armerin and Tomas Björk: Term Structure Models with Parallel and Proportional Shifts.

WP 2005-6 Ken L. Bechmann og Jesper Rangvid: Rating mutual funds:

Construction and information content of an investor-cost based rating of Danish mutual funds. 